Ann. Biol. anim. Bioch. Biophys., 1977, 17 (5 B), 923-952.

\title{
Développement morphologique et métabolique du tissu adipeux chez le porc : influence de la sélection, de l'alimentation et du mode d'élevage
}

\author{
par Y. HENRY
}

Station de Recherches sur l'Elevage des Porcs, I.N.R.A., 78350 jouy-en-josas.

Summary. Morphological and metabolic development of adipose tissue in the pig as affected by selection, feeding and management.

This report discusses the developmental characteristics of swine adipose tissue and the means of reducing carcass adiposity at slaughter by selection, feeding and management.

The pig has the highest degree of adiposity among meat animals. This is primarily a result of its highly developed subcutaneous depots ; nevertheless, the edible meat contains a relatively small amount of fat. This propensity of swine to excess adiposity, or even to obesity, is intensified in the castrated male. Obesity threshold is reached when the percentage of carcass fat exceeds that of muscle.

The very rapid development of adipose tissue in swine is associated with an almost exclusive hypertrophy of adipocytes after about 5 months of age, with marked variations according to age, adipose tissue site, sex and genetic type. This hypertrophy is especially noticeable in cases of obesity, including that of genetic origin.

The adipose tissue in swine is the almost exclusive site of fatty acid synthesis, as compared to the very low contribution of the liver. In general, the lipogenic activity is related to the intensity of fat deposition and the degree of adipose cell hypertrophy, which in turn depends on age, anatomical location, sex or genetic type. Recent studies on the mobilization of lipid stores have confirmed that swine adipose tissue is sensitive to lipolytic hormones of the catecholamine group, as to pituitary lipolytic polypeptides. The main factors regulating lipid accumulation in swine adipose tissue seem more related to lipogenesis than to lipolysis.

Among the factors of variation in swine adipose tissue development, the genetic factors were first considered ; they bring more or less prominent changes in morphological (cellularity) and metabolic (lipogenesis, lipolysis) processes. In extreme cases, the genetic-type obesity syndrome was mentioned. It seems to be mainly characterized by a stimulation of lipogenesis, gluconeogenesis and amino acid catabolism in the liver, along with a relative resistance of adipose tissue to insulin. The pig can be thus compared to a diabetic human.

On the other hand, a survey was made of animals exhibiting an accentuated muscular development up to the hypertrophy stage in the double-muscle pig. From the literature available on adipose tissue cellularity and lipogenesis, it seems that selection against adiposity brings about a delay in fat deposition, which appears to sustain the ability to develop up to a later stage of growth, following a reduction in muscle development potential. A more comprehensive role of genetic factors on pituitary and hormonal lipolytic factors could be a mean, through selected criteria, for early detection in live animals of the ability to produce lean carcasses as a result of their inability to store fat.

As regards nutritional factors, the limitation of carcass adiposity especially implies a quantitative control of feed intake, either by feed restriction according to muscle growth potential or by limiting the energy concentration in ad libitum feeding. The interdependence 
of genetic and nutritional factors in reducing adiposity was stressed. Again, two extreme cases were considered : fat-type pigs strongly rationed, but at a high cost, and highly muscled pigs ad libitum fed. Aside from these quantitative aspects of feeding, the kind of energy supply must be taken into account as well as feeding sequences, although the pig seems to be less sensitive than the rat to meal feeding.

There are few data on the effects of management on swine adipose tissue development. Changes in adipose tissue metabolic activities may occur at weaning when the diet is modified. The effects of management on carcass characteristics at slaughter have yet to be determined.

The practise of castration in male has been questioned and its suppression as a means of avoiding a strongly established case of obesity was suggested. As concerns management, the effects of ambient temperature on thermogenesis and thermolysis were discussed, depending on whether the animals were below or above the thermoneutral zone. In both cases, the changes occurring in adipose tissue metabolism are mostly due fo lipolysis, more generally attributable to stress such as intensive rearing.

\section{Introduction.}

Les progrès accomplis dans les connaissances sur le développement du tissu adipeux chez les animaux de laboratoire, comme chez l'homme, ont permis, au cours de ces dernières années, d'aborder l'étude de l'engraissement du porc sous un angle nouveau, non plus statique, par la simple mesure de l'importance des dépôts gras, mais essentiellement dynamique, en considérant à la fois les aspects morphologiques (cellularité) et métaboliques (lipogenèse, lipolyse). Cette nouvelle approche contribue à faire mieux comprendre les mécanismes présidant à la mise en place et à la réalisation des dépôts gras chez le Porc et surtout à définir les moyens permettant de parvenir à une parfaite maîtrise de l'état d'engraissement des carcasses à l'abattage et de là à accroître leur rendement en viande maigre, compte tenu de l'impact des facteurs génétiques, nutritionnels et du milieu.

Après avoir faił le point des particularités morphologiques ef métaboliques de l'évolution du tissu adipeux chez le porc, dans les conditions normales d'élevage et d'alimentation, nous traiterons de l'influence de la sélection, de l'alimentation et du mode d'élevage sur les divers aspects du développement des dépôts gras, en dégageant les moyens propres à améliorer les capacités de production en viande maigre. Les mises au point sur ce sujet sont très limitées. Parmi ces dernières, citons notamment celles de Henry (1975), Allen et al. (1976).

\section{Particularités morphologiques et métaboliques du développement du tissu adipeux chez le porc}

\section{Particularités de composition tissulaire.}

Parmi les animaux producteurs de viande, le porc est celui qui présente l'état d'adiposité le plus élevé. Le pourcentage de gras dans sa carcasse atteint normalement 40 p. 100 au stade habituel de la commercialisation, vers $100 \mathrm{~kg}$ de poids vif, contre 25 p. 100 chez les bovins (Schön, 1973). Par rapport au rat, le porc présente une adiposité deux fois plus élevée, à des stades physiologiques comparables : 
30 p. 100 de lipides par rapport au poids vide à $100 \mathrm{~kg}$ contre 15 p. 100 environ chez le rat mâle entier de $250 \mathrm{~g}$.

Les dépôts gras chez le porc, au poids de $100 \mathrm{~kg}$, représentent 82 p. 100 de l'énergie totale fixée dans l'organisme (Oslage et Fliegel, 1965). Sur les 20 à $35 \mathrm{~kg}$ de gras anatomiquement séparable, 70 p. 100 environ sont localisés dans la région souscutanée (dont le lard dorsal ou bardière) contre 20 à 25 p. 100 de gras intermusculaire et 5 p. 100 de gras interne périrénal (ou panne) ; le gras intramusculaire ne constitue qu'une fraction très faible des lipides corporels (1 à 2 p. 100).

La composition tissulaire de la carcasse du porc se caractérise ainsi par un rapport gras sous-cutané/gras intermusculaire (c'est-à-dire graisses externes/graisses internes) particulièrement élevé : entre 2 et 3 contre 0,2 à 0,6 chez les bovins, selon l'état d'engraissement des carcasses (Callow, 1948). Compte tenu de cette différence dans la localisation des dépôts gras, on n'observe pas de gros écarts dans la teneur en lipides de la partie musculaire, d'une espèce à l'autre, et ceci pour un état d'engraissement comparable (Lawrie, 1966). Il est en effet reconnu que dans une espèce donnée l'infiltration de graisse dans la fraction musculaire est en relation directe avec la teneur en graisses totales dans l'organisme (Callow, 1947). Cela signifie que si le porc présente une forte adiposité, l'excès de graisse est surtout localisé dans la partie séparable, de sorte qu'au stade de la consommation les différences entre les viandes produites sont fortement atténuées par rapport aux autres espèces.

En raison de l'importance du développement du tissu adipeux chez le porc, principalement au niveau sous-cutané, on peut donc s'interroger sur l'incidence de l'obésité chez cette espèce, au même titre que chez les animaux de laboratoire (rat, souris) et chez l'homme. L'évolution de la composition tissulaire des carcasses (tabl. 1) permet de définir d'une façon relativement précise le seuil d'apparition de l'obésité lorsque le rapport muscle/gras séparable devient inférieur à 1. A l'inverse, on peut constater que la sélection a conduit à un élargissement de l'étendue de la variation de la composition tissulaire, puisque le rapport muscle/graisse varie dans les limites de 1 ou moins chez les types obèses à plus de 4 chez les types de porcs à musculature hypertrophiée ou « culards».

TABLEAU 1

Variations de la composition tissulaire des carcasses de porcs ( $\left.{ }^{1}\right)$ (d'après Desmoulin et Pommeret, 1974, 1975)

\begin{tabular}{|c|c|c|c|c|}
\hline Type de porc & Maigre ( $\left.{ }^{2}\right)$ & Moyen & Gras & $\begin{array}{c}\text { Seuil } \\
\text { d'obésité }\end{array}$ \\
\hline p. 100 poids net & & & & \\
\hline- muscle $\ldots \ldots \ldots \ldots \ldots \ldots \ldots$ & $\begin{array}{l}65-55 \\
15-25\end{array}$ & $\begin{array}{l}55-45 \\
25-35\end{array}$ & $\begin{array}{l}<45 \\
>35\end{array}$ & $\begin{array}{l}40 \\
40\end{array}$ \\
\hline
\end{tabular}

(1) Animaux abattus à $100 \mathrm{~kg}$.

(2) Porc de type hypermusclé ou « culard ».

Les risques d'obésité chez le porc sont encore aggravés par la pratique de la castration du mâle (tabl. 2), qui affecte la moitié des 17 millions de porcs produits annuellement en France. L'obésité existe naturellement dans les races de porcs sauvages 
(sangliers) ou indigènes qui n'ont pas bénéficié des progrès de l'amélioration génétique. Mais elle apparaît également chez les porcs de type miniature, pour lesquels la sélection sur la petite taille, en vue de leur emploi pour la recherche biomédicale, s'est accompagnée d'une exagération de leur degré d'adiposité. Par ailleurs, l'obésité chez le porc peut être poussée à l'extrême à la suite de lésions hypothalamiques, entraînant simultanément une forte hyperphagie et un dérèglement des voies métaboliques (Auffray, 1975).

TABLEAU 2

Variations de la composition tissulaire des carcasses de porcs en fonction du sexe ef de la castration ( ${ }^{1}$ ) (d'après Desmoulin ef al., 1974)

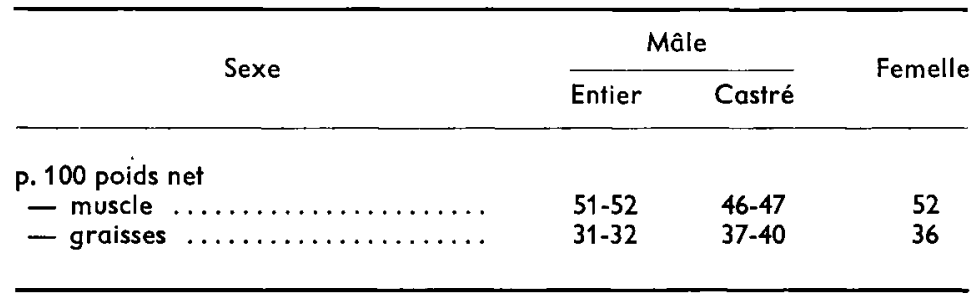

(1) Animaux de race Large White abattus à $100 \mathrm{~kg}$.

2. Cellularité du tissu adipeux.

Les premiers éléments du tissu adipeux chez le fotus de porc apparaissent aux environs du $70^{\mathrm{e}}$ jour de gestation dans les dépôts épididymaires et péricardiaques et vers le 106e jour dans le gras mésentérique (Vodovar et al., 1971 ; Desnoyers et Vodovar, 1974). A la naissance, les dépôts gras sont insignifiants puisqu'ils ne représentent que 1 à 2 p. 100 du poids vif et sont ainsi parmi les plus faibles de ceux observés à ce stade chez les mammifères. Par la suite, au contraire, la croissance postnatale du porc est caractérisée par un développement très important du tissu gras, dont le pourcentage par rapport au poids vif atteint rapidement $15 \mathrm{p} .100$ dès l'âge de deux mois (vers $15-20 \mathrm{~kg}$ ), 25 p. 100 à $50-60 \mathrm{~kg}$ et plus de 35 p. 100 vers $100 \mathrm{~kg}$.

2.1. Evolution globale. D'après les premières observations d'Anderson (1971), Anderson et Kauffman (1973a,b), confirmées par Hood (1972) et Steele (1973), le développement du tissu adipeux chez le porc se déroule en trois phases, caractérisées respectivement par une hyperplasie dominante entre 1 et 2 mois d'âge $(7-20 \mathrm{~kg})$, une hyperplasie et une hypertrophie entre 2 ef 5 mois $(20-70 \mathrm{~kg})$, ef une hypertrophie quasi exclusive au delà de 5 mois, soit plus de $70 \mathrm{~kg}$ (fig. 1). Toutefois, les cellules ainsi dénombrées après isolement à la collagénase et après fixation au tétroxyde d'osmium. ne comprennent pas celles d'un diamètre inférieur à $25 \mu$, si bien que leur nombre ne reflète pas l'hyperplasie véritable. Le nombre d'adipocytes chez le porc seraif fixé relativement tôt dans la vie de l'animal (Lee et al., 1973b), mais d'autres observations (Vodovar, communication personnelle) semblent indiquer qu'il y aurait une création de nouvelles cellules adipeuses jusqu'à un stade avancé de la croissance ( 220 jours d'âge). 
Selon Hood (1972), Hood et Allen (1977), l'accroissement du nombre total de cellules adipeuses chez des porcs de type amélioré (croisés Hampshire $\times$ Yorshire ef Minnesota $n^{\circ} 3 \times$ Minnesota $n^{\circ} 1$ ) est surtout net entre 50 et $80 \mathrm{~kg}$ de poids vif (soit entre 100 ef 140 jours d'âge), correspondant à la phase précédant la puberté, tandis que leur diamètre moyen (comme leur volume) est pratiquement inchangé.

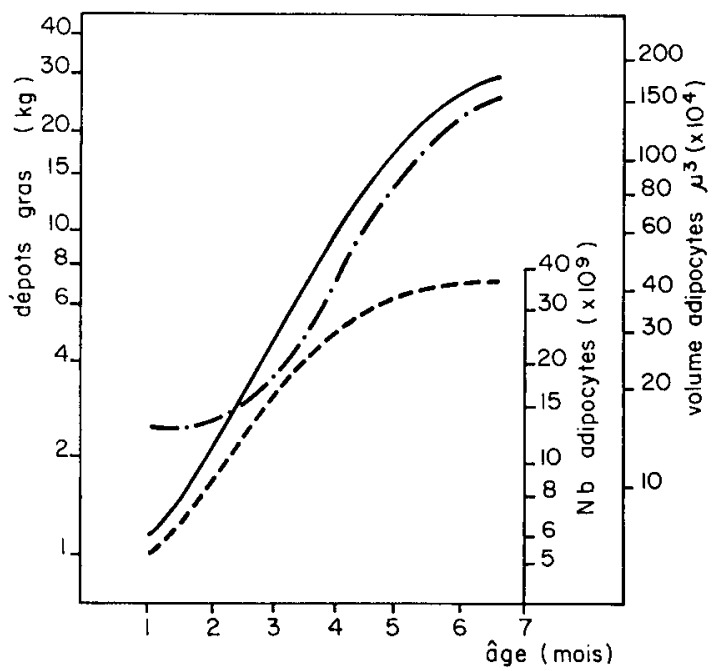

FIG. 1. - Développement morphologique du tissu adipeux chez le porc au cours de la croissance (Anderson et Kauffman, 1973a).

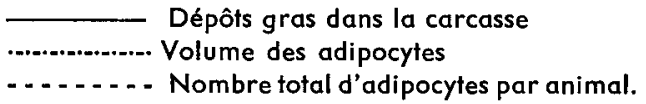

En définitive, l'accroissement des dépôts gras au cours de la croissance du porc est dô principalement à l'augmentation de la taille des adipocytes (tabl. 3 et 4). L'augmentation apparente du nombre total d'adipocytes pourrait résulter en réalité du

\section{TABLEAU 3}

Développement morphologique et métabolique du tissu adipeux chez le porc au cours de sa croissance $\left({ }^{1}\right)$ (Hood, 1972)

\begin{tabular}{|c|c|c|c|c|}
\hline $\begin{array}{l}\text { Poids vif }(\mathrm{kg}) \quad \ldots \ldots \ldots \ldots \ldots \ldots \ldots \ldots \ldots \\
\text { Age }(\mathrm{j}) \ldots \ldots \ldots \ldots \ldots \ldots \ldots \ldots \ldots\end{array}$ & $\begin{array}{l}28 \\
80\end{array}$ & $\begin{array}{l}54 \\
117\end{array}$ & $\begin{array}{r}83 \\
142\end{array}$ & $\begin{array}{l}109 \\
168\end{array}$ \\
\hline $\begin{array}{l}\text { Poids du dépôt gras extramusculaire }(\mathrm{kg}) \\
\text { Diamètre des adipocytes } \mu\left({ }^{2}\right) \ldots \ldots \\
\text { Volume des adipocytes } \mu^{3}\left(\times 10^{4}\right)\left({ }^{2}\right) \ldots \ldots \\
\text { Nombre total d'adipocytes }\left(\times 10^{9}\right) \ldots \ldots \\
\text { Activité de l'enzyme malique, nM substrat/ } \\
10^{6} \text { cellules }\left({ }^{2}\right) \ldots \ldots \ldots \ldots \ldots \ldots \ldots \ldots \ldots\end{array}$ & $\begin{array}{r}3,9 \\
63,0 \\
18,3 \\
25,4 \\
71,8\end{array}$ & $\begin{array}{r}9,7 \\
81,5 \\
35,9 \\
33,2 \\
128,0\end{array}$ & $\begin{array}{l}15,8 \\
78,8 \\
33,3 \\
58,6\end{array}$ & $\begin{array}{l}25,2 \\
91,8 \\
50,4 \\
64,5\end{array}$ \\
\hline
\end{tabular}

(1) Porcs mâles castrés Hampshire $\times$ Yorkshire.

(2) Lard dorsal (10 ${ }^{\mathrm{e}}$ côte), couche moyenne. 


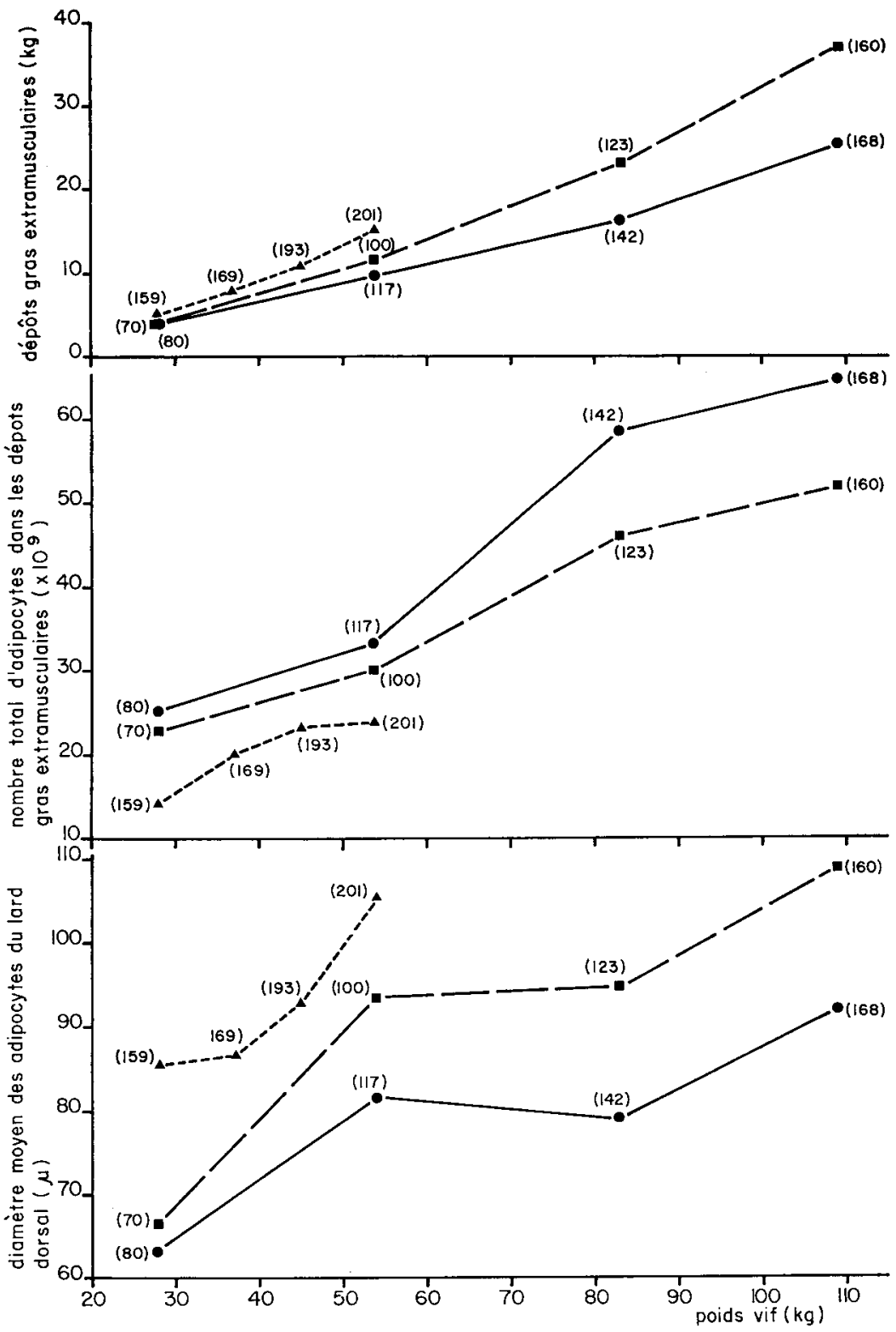

FIG. 2. - Evolution des dépôts gras extramusculaires au cours de la croissance, du nombre tofal d'adipocytes dans les dépôts gras extramusculaires ef du diamètre moyen des adipocytes dans la couche intermédiaire du lard dorsal (10e côte) chez des porcs de 3 types génétiques (d'après Hood, 1972 et Hood ef Allen, 1977).

$\longrightarrow$ croisés Hampshire $\times$ Yorkshire $(\mathrm{H} \times \mathrm{Y})$

- croisés Minnesota no $3 \times$ Minnesota no $1($ Minn. $3 \times 1)$

$\Delta-1-\Delta$ porcs miniatures Hormel (HM)

Entre parenthèses : âge des animaux en jours. 
TABLEAU 4

Evolution de la cellularité du tissu adipeux du porc au cours de sa croissance (1) (Mersmann ef al., 1975a)

\begin{tabular}{|c|c|c|c|c|c|c|c|c|}
\hline $\begin{array}{l}\text { Age }(j) \\
\text { Poids vif }(\mathrm{kg}) \ldots \ldots \ldots \ldots \ldots \ldots \ldots \ldots \ldots \ldots \\
\ldots\end{array}$ & $\begin{array}{c}0 \\
1,2\end{array}$ & $\stackrel{3}{1,5}$ & $\stackrel{9}{2,7}$ & $\begin{array}{l}\text { Sevra } \\
23 \\
4,8\end{array}$ & $\begin{array}{l}\left(^{2}\right) \\
40 \\
13,8\end{array}$ & $\begin{array}{l}60 \\
23,5\end{array}$ & $\begin{array}{l}110 \\
59,8\end{array}$ & $\begin{array}{r}160 \\
84,9\end{array}$ \\
\hline $\begin{array}{l}\text { Diamètre moyen des adipocytes } \mu\left(^{3}\right) \ldots \\
\text { Volume des adipocytes } \mu^{3}\left(\times 10^{4}\right) \ldots \ldots \\
\text { Nombre d'adipocytes }\left(\times 10^{6}\right) / g \ldots \ldots\end{array}$ & & $\begin{array}{r}24,1 \\
2,0 \\
7,5\end{array}$ & $\begin{array}{r}33,9 \\
4,9 \\
11,8\end{array}$ & $\begin{array}{r}35,7 \\
6,5 \\
11,1\end{array}$ & $\begin{array}{r}49,1 \\
11,3 \\
4,9\end{array}$ & $\begin{array}{r}48,6 \\
11,8 \\
5,8\end{array}$ & $\begin{array}{r}78,6 \\
43,9 \\
1,9\end{array}$ & $\begin{array}{r}70,1 \\
39,1 \\
2,5\end{array}$ \\
\hline
\end{tabular}

\footnotetext{
(1) Porcs croisés Chester White $\times$ Hampshire.

(2) Sevrage à 28-30 j d'âge.

( $\left.{ }^{3}\right)$ Lard dorsal, région médiane.
}

grossissement de petites cellules tout au long de la croissance (Mersmann et al., 1975). Ceci explique que la variabilité de la taille des adipocyłes diminue à mesure qu'augmente le poids des animaux (Hood, 1972).

D'une façon générale, on observe une relation relativement étroite entre la cellularité du tissu adipeux chez le porc et le degré d'adiposité de l'organisme (Tabl. 5) au fur et à mesure de l'accroissement de l'âge et du poids vif (Hood, 1972 ; Steele, 1973 ; Steele et al., 1974 ; Hoffmeister et Sink, 1974). De même, les travaux de Steele rapportent une corrélation significative entre la masse adipeuse dorsale ef le volume moyen des adipocytes $(r=+0,86)$, tandis que le même dépôt dorsal est en relation inverse avec le nombre d'adipocytes par $100 \mathrm{mg}$ de tissu $(r=-0,72)$.

\section{TABLEAU 5}

Relation entre la cellularité du tissu odipeux (gras périrénal) ef l'élat d'adiposité chez le porc : variations selon le stade de la croissance ef le type génétique (Hood, 1972)

\begin{tabular}{|c|c|c|c|c|c|}
\hline & Poids vif (kg) & 28 & 54 & 83 & 109 \\
\hline $\begin{array}{l}\text { Type } \\
\text { gras } \\
(1)\end{array}$ & $\begin{array}{l}\text { — Gras périrénal (p. } 100) \ldots \ldots \ldots \\
\text { - Diamètre moyen des adipocytes }(\mu)\end{array}$ & $\begin{array}{r}0,8 \\
66,6\end{array}$ & $\begin{array}{r}1,4 \\
93,5\end{array}$ & $\begin{array}{r}2,1 \\
94,8\end{array}$ & $\begin{array}{r}3,2 \\
108,9\end{array}$ \\
\hline $\begin{array}{l}\text { Type } \\
\text { maigre } \\
\left({ }^{2}\right)\end{array}$ & $\begin{array}{l}\text { — Gras périrénal }(p .100) \ldots \ldots \ldots \\
\text { — Diamètre moyen des adipocytes }(\mu)\end{array}$ & $\begin{array}{r}0,7 \\
63,0\end{array}$ & $\begin{array}{r}1,3 \\
81,5\end{array}$ & $\begin{array}{r}1,7 \\
78,8\end{array}$ & $\begin{array}{r}2,3 \\
91,8\end{array}$ \\
\hline
\end{tabular}

( $\left.{ }^{1}\right)$ Croisés Minnesola $n^{\circ} 3 \times$ Minnesota $n^{\circ} 1$.

(2) Croisés Hampshire $\times$ Yorkshire.

En ce qui concerne l'évolution du contenu cellulaire du tissu adipeux, l'hypertrophie des adipocytes s'accompagne généralement d'une diminution progressive de la teneur en protéines solubles par rapport au tissu frais (lard dorsal), tandis que la quantité de lipides par cellule augmente (Hood, 1972 ; Hood et Allen, 1973 ; Ander- 
son el Kauffman, 1973). Selon Schwandi et al. (1971), les teneurs en protéines solubles du tissu adipeux sont comparables chez le rat et chez l'homme (respectivement 21,7 et $21,0 \mathrm{mg} / \mathrm{g}$ de tissu frais), mais supérieures aux valeurs trouvées chez le porc $(5,4 \mathrm{mg} / \mathrm{g})$. Les mêmes auteurs pensent que l'accumulation de lipides dans les adipocytes, principalement sous la forme de trigycérides, se poursuit jusqu'à un point de saturation correspondant à $700 \mathrm{mg}$ de lipides par g de tissu frais. Ceci indique que les teneurs en eau et en lipides de tissu adipeux sont en relation avec sa maturité de développement (tabl. 6). On peut expliquer de la même façon l'apparition d'une distribution

\section{TABLEAU 6}

Variations de la composition des dépôts gras en fonction de leur maturité de développement chez le parc ( $\left.{ }^{1}\right)$ (Lee et Kauffmann, 1974b)

\begin{tabular}{|c|c|c|}
\hline Dépôłs & Eau (p. 100) & Lipides (p. 100) \\
\hline $\begin{array}{l}\text { Sous-cutané ............... } \\
\text { Intermusculaire } \ldots \ldots \ldots \ldots \ldots \\
\text { Intramusculaire } \ldots \ldots \ldots \ldots \ldots\end{array}$ & $\begin{array}{r}7,2 \\
10,3 \\
14,6\end{array}$ & $\begin{array}{l}91,7 \\
88,3 \\
83,4\end{array}$ \\
\hline
\end{tabular}

(1) Mâles castrés Duroc de $100 \mathrm{~kg}$.

bimodale des adipocytes lorsque les animaux atteignent un certain poids, généralement au delà de $100 \mathrm{~kg}$ et vers 150 jours d'âge (Allen ef al., 1974) : alors que le diamètre des cellules ne semble pas dépasser $200 \mu$, on trouve un nombre élevé d'adipocytes entre 25 et $50 \mu$, un nombre plus faible entre 50 et $75-100 \mu$, et une deuxième population de cellules entre 100 et $200 \mu$. L'existence d'une distribution biphasique des cellules adipeuses dès le début de la croissance, comme l'ont souligné Mersmann ef al. (1973b, 1975a, 1976), pourrait résulter d'une hétérogénéité dans la répartition des populations adipocytaires dans la couche de gras sous-cutané (Enser et al., 1976b).

2.2. Variations selon les dépôts. L'étude des variations de la cellularité en fonction de la localisation des dépôts a permis de montrer une relation directe entre l'intensité de développement de ces derniers ef la taille des adipocytes (Anderson ef al., 1972). Ce sont les dépôts où les lipides se fixent le plus rapidement qui ont les cellules les plus grosses, avec le plus de lipides par cellule ef le plus faible nombre de cellules par $\mathrm{g}$ de tissu frais. Ainsi, pendant la première partie de la croissance, les dépôts adipeux se développent dans l'ordre d'intensité décroissante : sous-cutané, mésentrique ef périrénal, intermusculaire, intramusculaire. Par exemple, d'après les données de Hood (1972), recueillies sur des porcs de $28 \mathrm{~kg}$, les adipocytes du gras périrénal ou panne (gras interne) ont un diamètre moyen inférieur à ceux du lard dorsal (gras externe). De la même façon, si l'on se réfère aux résultats de Lee ef al. (1973b), les adipocytes des dépôts sous-cutanés, abdominal et intramusculaire, chez les animaux de race Duroc de $80 \mathrm{~kg}$, ont pour diamètres respectifs en $\mu: 118 \pm 25,98 \pm 15$ et $65 \pm 13$ Le nombre total de cellules dans l'organisme, au même poids de $80 \mathrm{~kg}$, est 
de l'ordre de 40 à $5010^{9}$, dont 45 à 50 p. 100 sont localisées dans le gras sous-cutané et séparable, 41 à 47 p. 100 dans le gras intramusculaire (pour 12 p. 100 seulement des lipides corporels totaux), 3 à 4 p. 100 dans l'os et 5 à 7 p. 100 dans les viscères.

Utilisant des porcs Duroc mâles castrés de $100 \mathrm{~kg}$, Lee et Kauffman (1974b) mettent encore en évidence le développement tardif du gras intramusculaire par rapport au gras intermusculaire et surtout le dépôt sous-cutané. Après 16 semaines d'âge, ils observent toujours au niveau du gras intramusculaire une augmentation importante à la fois de la taille et du nombre de cellules. Ce phénomène d'hyperplasie semble même se prolonger d'unefaçon particulière dans ce dépôt au delà de 24 semaines, ce qui est en accord avec les observations effectuées sur bovins (Hood, 1972 ; Allen, 1976).

Dans le cas des porcs lourds de type gras, on se trouve par contre dans la phase de développement maximum du gras interne périrénal. Ainsi, dans un travail d'Anderson et al. (1972) sur mâles castrés de $170 \mathrm{~kg}$ issus du croisement Yorkshire $X$ Poland China, les cellules les plus grosses se situent dans le dépôt périrénal (diamètre : $153 \mu$ contre 129 à 134 dans le lard dorsal, au niveau de la 10 e côte).

Dans le gras sous-cutané lui-même (lard dorsal), ce sont les couches moyennes et internes qui contribuent le plus à la réalisation des dépôts et l'augmentation de taille des adipocytes y est plus rapide que dans la couche externe : c'est ce qu'observent Anderson et Kauffman (1973a) sur mâles castrés Chester White après 3 mois et demi d'âge, de même que Wood et al. (1975) sur des animaux Large White et Piétrain d'un poids compris entre 30 et $95 \mathrm{~kg}$. Par contre, chez des porcs de $170 \mathrm{~kg}$, Anderson et al. (1972) ne relèvent aucune différence dans le diamètre moyen des adipocyłes entre les couches externe, moyenne et interne du lard dorsal, au niveau de la $10^{\mathrm{e}}$ côte, soit respectivement 129, 134 et $131 \mu$. Plus récemment, Enser et al. (1976b) ont mis en évidence un gradient dans la taille des cellules adipeuses du lard dorsal, les plus petites cellules se trouvant immédiatement sous la peau ef au contact du muscle et les plus grosses de part et d'autre du tissu conjonctif séparant les couches externe et interne. Cette hétérogénéité très marquée dans la répartition des populations d'adipocytes dans l'épaisseur du gras sous-cutané met en lumière les difficultés d'échantillonnage en vue des observations morphologiques et métaboliques.

Il est intéressant de remarquer que les variations de cellularité selon la localisation sont accompagnées d'une différence dans la composition des dépôts en acides gras, les dépôts externes étant plus riches en acides gras insaturés que les dépôts internes (Sink ef al., 1964). Il en est de même de la couche externe du lard dorsal visà-vis des couches moyenne et interne (Wood, 1973), le degré d'insaturation étant d'ailleurs plus marqué chez les types de porc à fort développement musculaire (Piétrain) que chez ceux de type gras.

2.3. Variations selon le sexe et la castration. L'obésité induite par la castration du mâle se manifeste principalement par une hypertrophie des cellules adipeuses, comme l'ont observé Lee ef al. (1973b) chez des castrats de race Poland China de $80 \mathrm{~kg}$ : ces derniers présentent une taille moyenne d'adipocytes plus élevée que les femelles, bien que renfermant au total moins de cellules. Ces résultats confirment une fois de plus que, chez le porc, la taille des cellules apparaît comme un facteur déterminant dans le développement ultime de la masse adipeuse. 
3. Activités méfaboliques du tissu adipeux.

L'accumulation des lipides corporels est la résultante de deux processus :

- le dépôt de lipides alimentaires ef la synthèse de novo d'acides gras, principalement à partir des glucides.

- la mobilisation des lipides stockés par le processus de la lipolyse.

\subsection{Lipogenèse.}

- Contributions du tissu adipeux ef du foie à la synthèse des lipides.

Le fissu adipeux chez le porc est le site majeur, sinon exclusif, de la synthèse de novo des lipides, contrairement à la conception classique qui attribuait au foie un rôle surestimé.

Wierzuchowski et Ling (1925) enregistraient déjà chez cet animal des quotients respiratoires $(Q R)$ très élevés, indicatifs d'une lipogenèse intense. Faisant l'hypothèse que les lipides alimentaires sont déposés en totalité, Hood (1972) estime la contribution du tissu adipeux du porc dans la synthèse de novo des lipides corporels à 74 et 84 p. 100 respectivement, selon qu'il s'agit de croisés Hampshire $\times$ Yorkshire ou Minnesota $3 \times 1$, entre 28 et $109 \mathrm{~kg}$ de poids vif.

Dans le cas particulier de l'utilisation du glucose, qui constitue le principal précurseur physiologique des acides gras chez le porc par l'intermédiaire de l'amidon, la part des lipides synthétisés in situ dans le tissu adipeux s'élèverait même à plus de 99 p. 100 d'après les travaux d'O'Hea (1969), O'Hea et Leveille (1969 a). Lorsqu'on utilise comme substrat de l'acétate au lieu du glucose, ces auteurs observent par contre une incorporation beaucoup plus forte dans les lipides du foie de porcs mâles entiers Yorkshire $x$ Duroc, que ce soit in vitro ou in vivo, comple tenu notamment de l'importance de la synthèse du cholestérol au niveau hépatique. Quoi qu'il en soit, la capacité du tissu adipeux à transformer l'acétate en acides gras est 10 fois plus élevée que celle du foie. La contribution du tissu adipeux à la synthèse des lipides est alors de 70-75 p. 100 contre 25-30 p. 100 pour le foie. Ce dernier, cependant, peut jouer un rôle plus important dans la lipogenèse si l'acétate est disponible sous forme libre, ce qui est le cas lors de la dégradation des substances cellulosiques par voie microbienne. Comme l'acétate, le propionate et le lactate sont captés d'une façon privilégiée par le foie pour la synthèse lipidique. Les observations récentes de Mersmann et al. (1973c;1976a) confirment par ailleurs le faible taux d'incorporation in vitro du glucose ou de l'acétate dans le foie, comparativement au tissu adipeux.

Pour ce qui est des contributions respectives du tissu adipeux et du foie à la synthèse des lipides, le porc se différencie des autres espèces, notamment du rat, chez lequel le tissu adipeux contribue pour 50 p. 100 environ dans la synthèse des acides gras et surtout le poulet, dont le foie participe pour plus de 90 p. 100 (O'Hea, 1969 ; Leveille ef al., 1975).

La capacité limitée du foie du porc à transformer le glucose en lipides, comparativement à l'acétate, explique le très faible niveau des activités des enzymes à NADPH liées à la lipogenèse : glucose-6-phosphate déshydrogénase (G-6-PDH), 6-phosphogluconate déshydrogénase (6-P-GDH) et enzyme malique (ME), à l'exception toutefois de l'isocitrate déshydrogénase $(\mathrm{ICDH})$, comme l'ont montré O'Hea et Leveille (1969a), Wolfe et al. (1973) et Rogdakis (1974 b). II en est de même pour l'acide 
gras synthélase et l'enzyme de coupure du citrate (CCE), qui est essentielle pour la production d'acétyl CoA cytoplasmique, mais pratiquement absente dans le foie.

- Evolution de l'activité lipogénique du tissu adipeux au cours de la croissance.

D'une façon générale, l'intensité de la lipogenèse in vitro chez le porc, qu'elle soit mesurée par les activités des enzymes à NADPH (enzymes du cycle des pentoses, enzyme malique) ou par l'incorporation d'un substrat marqué (glucose- $U-{ }^{14} \mathrm{C}$, acétate $1{ }^{14} \mathrm{C}$ ) dans les constituants lipidiques (acides gras, glycérol, insaponifiable) est indicative de l'état d'engraissement des animaux et plus précisément de la taille des adipocytes (O'Hea et Leveille, 1970 ; Anderson ef al., 1972 ; Rogdakis, 1973, 1975). Il en est ainsi lorsque l'on considère l'évolution des dépôts gras au cours de la croissance ou les variations selon leur localisation (Anderson et al., 1972 ; Anderson et Kauffman, 1973 ; Rogdakis, 1974), de même que les variations en fonction du sexe et de la castrotion (Allee et al., 1972 : tabl. 7 ; Rogdakis, 1974b), ou encore en fonction du type génétique (Hood, 1972 ; Hood et Allen, 1973 ; Stelle, 1973 ; Steele et al., 1974).

\section{TABLEAU 7}

Influence du sexe et de la castration sur l'activité lipogénique du fissu adipeux chez le porc (Allee ef al., 1972)

\begin{tabular}{|c|c|c|}
\hline Sexe & Femelles & Mâles castrés \\
\hline 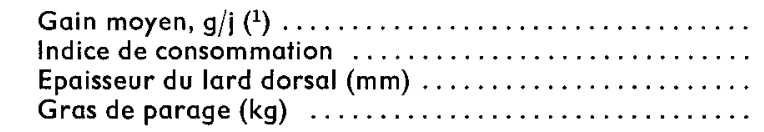 & $\begin{array}{c}704 \\
2,58 \\
35,9 \\
6,64\end{array}$ & $\begin{array}{c}777 *\left({ }^{2}\right) \\
2,79 * \\
40,7 * \\
7,19\end{array}$ \\
\hline \multicolumn{3}{|l|}{ Utilisation du glucose- $U-{ }^{14} \mathrm{C}$ in vitro $\left(^{3}\right)$} \\
\hline $\begin{array}{l}\text { Incorporation dans les ac. gras, } \mathrm{nM} / 100 \mathrm{mg} \text { tissu frais } / 2 \mathrm{~h} \ldots \\
\text { Oxydation en } \mathrm{CO}_{2}, \mathrm{nM} / 100 \mathrm{mg} \text { tissu frais } / 2 \mathrm{~h} \quad \ldots \ldots \ldots \ldots\end{array}$ & $\begin{array}{l}289 \\
160\end{array}$ & $\begin{array}{l}337 * \\
173 *\end{array}$ \\
\hline \multicolumn{3}{|l|}{ Activité enzymatique, nM substrat/mn/mg protéines $\left({ }^{3}\right) \ldots \ldots$} \\
\hline $\begin{array}{l}\text { Enzyme malique } \ldots \ldots \ldots \ldots \ldots \ldots \ldots \ldots \ldots \ldots \ldots \ldots \ldots \ldots \ldots \ldots \ldots \ldots \ldots \ldots \ldots \ldots \ldots \\
\text { Enzyme de coupure du citrate } \ldots \ldots \ldots \ldots \ldots \ldots \ldots \ldots\end{array}$ & $\begin{array}{r}125 \\
27\end{array}$ & $\begin{array}{r}154 * \\
35 *\end{array}$ \\
\hline
\end{tabular}

(1) Entre 44 ef $94 \mathrm{~kg}$.

$\left(^{2}\right) *$ : Différence significative au seuil 0,05 .

(3) Lard dorsal (au niveau de l'épaule, couche externe).

Les résultats de Hood (1972) ont fait apparaître une relation approximativement linéaire entre les activités des enzymes à NADPH sur la base cellulaire et le diamètre moyen des adipocytes chez 3 types de porcs très différents du point de vue génétique. Cependant, comme le font remarquer Mersmann ef al. (1975), la prise en considération des cellules de petite taille (d'un diamètre inférieur à $25 \mu$ ), ce qui n'a pas été le cas dans cette étude, pourrait modifier l'évolution de l'activité lipogénique sur la base cellulaire. C'est également le point de vue de Deb et al. (1973), qui pensent que la 
capacité de synthèse serait maximale pour des adipocytes de taille intermédiaire et décroîtrait dans les cas extrêmes (cellules très petites ou très grosses).

Sur le plan hormonal, le métabolisme du tissu adipeux chez le porc est caractérisé par une relative insensibilité à l'insuline. C'est ce qui ressort d'observations in vitro (O'Hea et Leveille, 1968 ; Wangsness et Martin 1975), quoique la réponse à l'insuline serait plus forte pendant le jeune âge (O'Hea et Leveille, 1970). Un épuisement des réserves d'insuline, soit in vitro, après pré-incubation de coupes de tissu adipeux en présence de sérum anti-insuline porcin, soit in vivo par injection d'alloxane ou de streptozytocine (O'Hea et Leveille, 1970), permet cependant une restauration de la réponse à l'insuline, sur le plan de la capacité lipogénique (utilisation de glucose U- ${ }^{14} \mathrm{C}$ in vitro pour la synthèse des acides gras). On sait par ailleurs que la pancréatectomie chez le porc n'entraîne pas de diabète sévère comme chez les autres animaux (Gould ef Carlson, 1911 ; Lukens, 1937).

De la même façon, une surcharge en glucose chez le porc ne provoque qu'une faible élévation de l'insulinémie (Machlin et al., 1968). L'excès d'adiposité du porc ne serait pas la conséquence d'une hypersécrétion d'insuline comme chez l'obèse humain. Sur ce plan, le porc peut être comparé au sujet humain diabétique, en raison notamment de la similitude de la courbe de tolérance au glucose. D'après les mêmes auteurs, une injection d'insuline par voie intraveineuse $(0,3 \mathrm{Ul} / \mathrm{kg}$ de poids vif) à des porcs de $45-75 \mathrm{~kg}$, après un jeûne d'une nuit, provoque une hypoglycémie pendant les $30 \mathrm{mn}$ suivant l'injection, mais l'augmentation du taux d'hormone de croissance dans le sang, consécutive à cette hypoglycémie, est relativement faible par rapport aux taux de réponse observés habituellement chez l'homme.

\subsection{Lipolyse.}

La mobilisation des lipides correspond surtout à l'hydrolyse des triglycérides intracellulaires en leurs deux composants, acides gras et glycérol.

Pour ce qui concerne l'hydrolyse des triglycérides circulants (chylomicrons d'origine principalement exogène, lipoprotéines d'origine essentiellement endogène), l'activité de la lipoprotéine lipase se trouve en relation directe avec l'intensité du dépôt de lipides corporels (Weisenburg et Allen, 1973 ; Lee et Kauffman, 1974).

L'hydrolyse des triglycérides intracellulaires met surtout en œuvre la lipase hormonosensible, dont l'activité au cours de la période périnatale est déjà plus forte chez le porc sauvage (sanglier) que chez le porc domestique, ceci en raison d'une activité physique plus intense pour les besoins de la thermorégulation ef un degré de maturité de son tissu adipeux plus avancé (Horn et al., 1973).

La réponse du tissu adipeux aux agents lipolytiques fait intervenir deux groupes de substances, selon qu'elles agissent au niveau des systèmes adénylcyclasique (hormones) ou phosphodiestérasique (méthylxanthines).

Dans des essais in vitro, Rudman et Di Girolamo (1967) concluent à l'absence de réponse du tissu adipeux du porc aux hormones lipolytiques courantes (polypeptides pituitaires, catécholamines) à la différence des autres espèces animales, comme le lapin, le cobaye le hamster, le rat ef le chien. Par contre, Trygstad ef al. (1972), Weisenburg et Allen (1973) ont mis en évidence la stimulation de l'activité lipolytique du tissu adipeux du porc par l'adrénaline. D'après Mersmann et al. $(1974,1975 b)$, les 
récepteurs de la lipase hormono-sensible sonf essentiellement du type adrénergique et du point de vue de leur efficacité in vitro les catécholamines se classent dans l'ordre décroissant : isoprotérénol, noradrénaline et adrénaline, c'est-à-dire de la même façon que chez le rat.

L'activité lipolytique du tissu adipeux chez le porc présente une évolution particulière au cours de sa croissance. Mesurée en $\mu$ moles d'acides gras libérés par $g$ de tissu frais, dans les conditions d'incubation in vitro, elle augmente très brutalement entre la naissance et deux jours d'âge, parallèlement à l'accroissement des dépôts gras, puis se maintient à un niveau élevé pendant les premières semaines de vie de l'animal (jusqu'à 45 jours), pour décliner fortement par la suite (Mersmann et al., $1975 a, 1976 b)$. La même diminution est observée lorsque l'activité lipogénique est exprimée sur la base cellulaire, tout au moins en fin de croissance. Ces résultats, qui demandent à être confirmés, semblent en contradiction avec ceux enregistrés sur des jeunes rats à croissance rapide (Zinder et Shapiro, 1971) et chez l'homme (Jacobson et Smith, 1972) montrant une relation directe entre la lipolyse et la taille de la cellule adipeuse. Ils sont par contre en accord avec ceux de Knittle et Hirsch (1968) obtenus sur des rats adultes. Cefte différence peut résulter de l'évolution des sites récepteurs de la membrane de l'adipocyte au cours de la croissance.

Dans les conditions d'étude in vivo, Cunningham et Friend (1965) confirment l'action lipolytique de l'adrénaline et de la noradrénaline, la réponse à l'injection hormonale étant plus forte chez les porcs de $80 \mathrm{~kg}$, comparativement à ceux de $25 \mathrm{~kg}$. La même observation est faite par Hertelendy ef al. (1966), qui procèdent à une infusion d'adrénaline de plus ou moins longue durée $(1 \mathrm{~h}$ et $6 \mathrm{~h}$ ) sur des porcs de $25-50 \mathrm{~kg}$ après un jeûne de $18 \mathrm{~h}$ et sous anesthésie au pentobarbital. L'élévation du taux d'acides gras libres dans le sang est accompagnée d'une hyperglycémie pendant toute la période d'infusion, tandis que l'insulinémie est maintenue à un niveau bas, ce qui signifie un blocage de la libération d'insuline par l'adrénaline. Plus récemment, Persson et al. (1971), puis Stanton et Mueller $(1973 a, b)$ corroborent l'effet lipolytique des catécholamines (adrénaline, noradrénaline, isoprotérénol) après injection à de jeunes porcelets, tandis que Wood (1974) note également une sensibilité particulière du tissu adipeux du porc à la noradrénaline, après infusion pendant une heure à la dose de $5 \mathrm{mg} / \mathrm{kg}$ de poids vif chez des animaux de $40-50 \mathrm{~kg}$.

De la même façon, selon Buzzell ef al. (1975), une infusion d'hormone de croissance dans la veine jugulaire de porcs mâles castrés de $69-77 \mathrm{~kg}$ entraîne une stimulation de l'activité lipolytique (élévation de la concentration en acides gras libres du sang), accompagnée d'une augmentation de la glycémie et de l'insulinémie, mais la présence de cette hormone ne semble pas nécessaire pour déclencher la mobilisation des acides gras pendant le jeûne. Il a été montré par ailleurs que l'insuline exerce un effet antilipolytique chez le porc, en réduisant la concentration en AMP cyclique (Weisenburg et Allen, 1973).

Au niveau hypophysaire, les travaux récents de Tamasi ef al. (1969), Desranleau ef al. (1972), Schwandt et al. (1973) ont permis l'isolement chez le porc d'un facteur lipolytique de nature polypeptidique appelé « lipotropic hormone» ( $\beta$-LPH), qui est très proche des $\beta$-LPH ovines du point de vue tant de la constitution que de l'immunologie, mais différente de la $\beta$-LPH humaine. 


\section{Facteurs de variation et maîtrise du développement du tissu adipeux et de l'état d'engraissement du porc}

Le porc est un animal naturellement gras et les efforts des généticiens, comme des nutritionnistes et des zootechniciens, ont contribué à réduire son état d'adiposité afin d'adapter la production de viande porcine aux exigences du consommateur.

\section{Variations génétiques.}

Parallèlement aux variations du profil de la croissance tissulaire et de l'état d'engraissement des carcasses à l'abattage, les facteurs génétiques induisent des modifications plus ou moins importantes des caractéristiques morphologiques ef métaboliques du tissu adipeux, allant dans les cas extrêmes de l'obésité, dans les types de porcs non sélectionnés, à l'hypertrophie musculaire, à la suite d'une sélection intense sur le développement des tissus maigres. Si le syndrome de l'obésité de type génétique est intéressant à connaître, ne serait-ce que par ses prolongements en recherche biomédicale, l'objectif qu'on doit se fixer en élevage est avant tout de disposer de critères de sélection suffisamment précis pour mieux contrôler les voies du métabolisme du tissu adipeux.

\subsection{Obésité de type génétique dans l'espèce porcine.}

Sur le plan de la cellularité, l'obésité d'origine génétique chez le porc est caractérisée essentiellement par une hypertrophie des cellules adipeuses et se distingue ainsi de celle décrite chez les rongeurs (souris ob/ob, rat $f a / f a$ ), laquelle se traduit à la fois par une hypertrophie et une hyperplasie (Bray et al., 1974). Mais chez le porc, les races naturellement grasses mises à part et contrairement aux animaux de laboratoire, aucune sélection sur l'obésité n'a été effectuée.

Les travaux de Hood (1972), Hood et Allen (1973), ont montré par exemple que pendant la croissance les différences d'adiposité entre les porcs de type maigre (croisés Hampshire $\times$ Yorkshire) et ceux de type gras (croisés Minnesota $3 \times 1$ ou porc miniature Hormel) sont dues uniquement à l'hypertrophie et non à l'hyperplasie (tabl. 8 ; fig. 2).

TABLEAU 8

Variation génétique de la cellularité du tissu adipeux chez le porc (1) (Hood, 1972)

\begin{tabular}{|c|c|c|}
\hline Type génétique & $\begin{array}{c}\text { Maigre } \\
H \times Y\left({ }^{2}\right)\end{array}$ & $\begin{array}{c}\text { Gras } \\
\operatorname{Minn} 3 \times 1\left(^{3}\right)\end{array}$ \\
\hline $\begin{array}{l}\text { Gras extramusculaire }(p .100) \ldots \ldots \ldots \ldots \ldots \ldots \ldots \ldots \ldots \\
\text { Diamètre des adipocytes }(\mu) \ldots \ldots \ldots \ldots \ldots \ldots \ldots \\
\text { Volume des adipocytes, } \mu^{3}\left(\times 10^{4}\right) \ldots \ldots \ldots \ldots \ldots \ldots \\
\text { Nombre adipocytes } / g \text { tissu adipeux }\left(\times 10^{6}\right) \ldots \ldots \ldots \ldots \ldots \\
\text { Nombre total d'adipocytes dans la carcasse }\left(\times 10^{9}\right) \ldots \ldots\end{array}$ & $\begin{array}{l}30,6 \\
91,8 \pm 1,7 \\
50,4 \pm 3,2 \\
2,4 \pm 0,2 \\
71,1\end{array}$ & $\begin{array}{l}46,6 \\
108,9 \pm 2,2 \\
90,5 \pm 4,8 \\
1,3 \pm 0,1 \\
56,4\end{array}$ \\
\hline
\end{tabular}

(1) Mâles castrés abattus à $109 \mathrm{~kg}$.

(2) Croisés Hampshire $\times$ Yorkshire.

(3) Croisés Minnesota no $3 \times$ Minnesota no 1 . 
L'influence d'un jeône prolongé à un stade tardif de la croissance fait également apparaître des différences selon le degré d'adiposité des souches utilisées (Hood, 1972). Si d'une manière générale la diminution des dépôts gras qui en résulte esł accompagnée d'une réduction du diamètre des adipocytes, mais sans changement du nombre total des cellules, la réponse est plus forte chez les animaux de type maigre (Hampshire $\times$ Yorkshire) que chez ceux de type gras (Minnesota $3 \times 1$ ), ce qui semble indiquer une capacité plus grande à mobiliser et à utiliser les graisses de réserve. L'apparition d'un nombre accru d'adipocyłes d'un diamètre supérieur à $25 \mu$ chez les porcs de type gras pourrait résulter d'une mobilisation des acides gras à partir de grosses cellules, suivie d'un redépôt dans les préadipocytes d'un diamètre inférieur à $25 \mu$.

Les conséquences de l'obésité au plan métabolique ont été étudiées par Martin ef al. (1973), dans une étude comparant des porcs maigres de race améliorée (Yorkshire) et de type obèse, d'une race indigène de Géorgie (Ossabaw), à 5 mois d'âge et aux poids respectifs de 93 et $58 \mathrm{~kg}$. Dans le dépôt gras périrénal, comme dans le tissu adipeux sous-cutané, les activités spécifiques des enzymes de la lipogenèse sont plus élevées chez les animaux obèse (tabl. 9). Il en est de même de l'activité de la fructose diphosphatase, ce qui indiquerait une gluconéogenèse plus intense. Au niveau hépatique, on observe de la même façon une augmentation des activités des enzymes de la gluconéogenèse et du métabolisme des acides aminés (aspartate aminotransférase). La stimulation de la gluconéogenèse chez les porcs obèses a éfé démontrée par la mesure de l'incorporation in vitro de l'alanine dans le glucose du tissu hépatique (Martin et Herbein, 1976). Remarquons toutefois que cette stimulation de la gluconéogenèse observée chez l'animal obèse, au développement musculaire plus faible, peut être, au moins en partie, la conséquence d'un excès relatif des protéines par rapport à l'énergie, comme l'ont souligné Peret et al., (1975).

TABLEAU 9

Caractérisation métabolique du syndrome d'obésité chez le porc (MARTIN ef al., 1973)

\begin{tabular}{|c|c|c|}
\hline $\begin{array}{l}\text { Type de porc } \\
\text { Race }\end{array}$ & $\begin{array}{l}\text { Maigre } \\
\text { Yorkshire }\end{array}$ & $\begin{array}{l}\text { Obèse } \\
\text { Ossabaw }\end{array}$ \\
\hline $\begin{array}{l}\text { Poids vif }(\mathrm{kg}) \text { à } 5 \text { mois d'âge } \ldots \ldots \ldots \ldots \ldots \ldots \ldots \ldots \ldots \ldots \ldots \\
\text { Epaisseur du lard dorsal }(\mathrm{cm}) \quad \ldots \ldots \ldots \ldots \ldots \ldots \ldots \ldots \\
\text { Foie }\end{array}$ & $\begin{array}{r}92,6 \pm 2,6 \\
2,8 \pm 0,2\end{array}$ & $\begin{array}{r}58,0 \pm 4,3 \\
8,1 \pm 0,2\end{array}$ \\
\hline 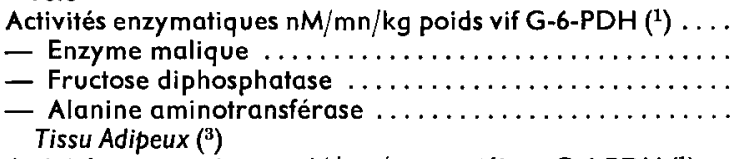 & $\begin{array}{l}12,8 \pm 1,8 \\
15,2 \pm 0,7 \\
75,6 \pm 4,6 \\
20,3 \pm 0,8\end{array}$ & $\begin{array}{l}13,0 \pm 1,7 \mathrm{NS}\left({ }^{2}\right) \\
12,8 \pm 2,1 \mathrm{NS} \\
124,2 \pm 13,0 * * \\
39,0 \pm 2,5 * *\end{array}$ \\
\hline $\begin{array}{l}\text { Activités enzymatiques, } \mathrm{nM} / \mathrm{mn} / \mathrm{mg} \text { protéines } \mathrm{G}-6 \mathrm{PDH}\left({ }^{1}\right) \ldots \\
\text { - Enzyme malique } \ldots \ldots \ldots \ldots \ldots \ldots \ldots \ldots \ldots \ldots \ldots \ldots\end{array}$ & $\begin{array}{r}95 \pm 8 \\
143 \pm 18\end{array}$ & $\begin{array}{l}145 \pm 20 * \\
344 \pm 59 *\end{array}$ \\
\hline
\end{tabular}

(1) Glucose-6-Phosphate déshydrogénase.

(2) Seuils de signification :**:0,01;*:0,05; NS : différence non significative.

(3) Lard dorsal. 
Les travaux de Hood (1972) ont montré de leur côté que les activités des enzymes à NADPH, exprimées par $10^{6}$ cellules, sont plus élevées tout au long de la croissance chez les porcs à forte adiposité que chez ceux de type maigre. Parmi les enzymes à NADPH, l'ICDH devient même adaptative dans le cas d'obésité, alors qu'elle ne l'est pas dans les conditions normales. Des différences génétiques apparaissent de la même façon au niveau des enzymes qui assurent la fourniture de substrats pour la lipogenèse, sous la forme d'acétyl CoA ou de malonyl CoA. Il en est ainsi en particulier de l'acétyl CoA carboxylase, dont l'activité est plus élevée chez les porcs de type gras (tabl. 10).

TABLEAU 10

Influence du type génétique sur l'activité lipogénique du tissu adipeux chez le porc : acety/ CoA carboxylase (1) (Hood et Allen, 1973)

\begin{tabular}{|c|c|c|}
\hline Type génétique $\left({ }^{2}\right)$ & $\begin{array}{l}\text { Maigre } \\
H \times Y\end{array}$ & $\begin{array}{c}\text { Gras } \\
\text { Minn. } 3 \times 1\end{array}$ \\
\hline $\begin{array}{l}\text { Lard dorsal }\left(10^{e} \text { côte) }\right. \\
- \text { Couche externe } \ldots \ldots \ldots \ldots \ldots \ldots \ldots \ldots \ldots \ldots \ldots \ldots \\
\text { - Couche moyenne } \ldots \ldots \ldots \ldots \ldots \ldots \ldots \ldots \ldots \ldots \ldots \ldots\end{array}$ & $\begin{array}{r}3,69 \\
3,98 \\
15,70\end{array}$ & $\begin{array}{r}4,02 \\
11,45 \\
12,85\end{array}$ \\
\hline
\end{tabular}

(1) $\mathrm{nM} \mathrm{HCO}_{3}$ fixées $/ \mathrm{mn} / 10^{6}$ cellules.

(2) Animaux de $109 \mathrm{~kg}$.

$\mathrm{H} \times \mathrm{Y}$ : croisés Hampshire $\times$ Yorkshire.

Min. $3 \times 1$ : croisés Minnesota no $3 \times$ Minnesota $n^{\circ} 1$.

Une autre caractérisation du syndrôme de l'obésité chez le porc a été obtenue par l'étude de l'influence du jeûne ef de la réalimentation sur les activités métaboliques du tissu adipeux. La réponse adaptative des enzymes à NADPH du tissu adipeux à ce type d'alternance (O'Hea et Leveille, 1969b ; Rogdakis, 1974b) n'est pas retrouvée, semble-t-il, chez le porc obèse (Martin et al., 1973).

L'activité de la lipoprotéine lipase, exprimée sur la base cellulaire (par rapport à la teneur en DNA), est plus élevée chez les porcs obèses que chez les animaux de type maigre, ce qui est conforme à son évolution en fonction de l'intensité des dépôts gras (Weisenburg et Allen, 1973). De même, son accroissement après traitement insulinique chez les porcs maigres n'apparaît pas chez ceux de type obèse, comme après injection d'héparine.

1.2. Conséquences de la sélection pour le développement musculaire et/ou contre l'adiposité.

Les progrès réalisés dans le domaine de l'amélioration génétique ont permis d'abaisser dans des proportions considérables l'état d'engraissement des carcasses, ce qui n'a pas été sans conséquence sur la morphologie et le métabolisme du tissu adipeux.

C'est ce qui apparaî̀ dans la comparaison de deux types génétiques nettement différenciés : le Porc Large White, de type gras, ef le porc de Piétrain dit culard, c'est- 
à-dire présentant une musculature hypertrophiée et un faible état d'engraissement. Dès la naissance ef pendant la phase initiale de la croissance (entre la naissance ef l'âge de 28 jours) les résultats de Moody ef al. (1975a et b), Enser ef al. (1976a) font ressortir, chez le Large White, une augmentation plus forte du diamètre moyen des adipocytes du lard dorsal que chez le Piétrain, parallèlement à l'accroissement de l'épaisseur du lard à ce niveau (tabl. 11). A ce stade, les cellules adipeuses du gras intramusculaire (muscles long dorsal, semi-tendineux et semi-membraneux) sont également plus grosses et plus nombreuses chez les porcelets Large White. Les observations de Wood ef al. (1975) sur les mêmes races de porcs traduisent une évolution particulière de la cellularité du tissu adipeux selon la race, en relation notamment avec la précocité de son développement (tabl. 12). Alors qu'à $30 \mathrm{~kg}$ de poids vif, les porcs de race Large White ont des adipocytes de plus grand diamètre que les animaux Piétrain, par la suite le développement plus tardif du tissu adipeux chez les Piétrain se traduit par une augmentation plus rapide de la taille des cellules pour atteindre et même dépasser les valeurs observées chez les animaux de race Large White au poids de $95 \mathrm{~kg}$. Nous avons remarqué de la même façon, dans le cas de femelles abattues à $95 \mathrm{~kg}$, que l'activité lipogénique du tissu adipeux in vitro présente une intensité comparable chez des animaux de type Landrace Français et Piétrain, tandis qu'elle est plus faible chez les animaux de type Landrace Belge, en raison probablement d'un développement plus tardif de leur tissu adipeux.

\section{TABLEAU 11}

Influence de la race sur la cellularifé du tissu adipeux du porc : résultats entre la naissance ef l'âge de $28 \mathrm{j}$ (Enser et al., 1976a)

\begin{tabular}{|c|c|c|c|c|}
\hline \multirow{2}{*}{$\begin{array}{l}\text { Race } \\
\text { Age }\end{array}$} & \multicolumn{2}{|c|}{ Large White } & \multicolumn{2}{|c|}{ Piétrain } \\
\hline & Naissance & $28 \mathrm{j}$ & Naissance & $28 j$ \\
\hline $\begin{array}{l}\text { Epaisseur du lard dorsal }(\mathrm{mm}) \ldots \ldots \ldots \ldots \ldots \ldots \\
\text { Diamètre moyen des adipocytes, } \mu\left({ }^{(}\right) \ldots \ldots \ldots \ldots \\
(1) \text { Lard dorsal. }\end{array}$ & $\begin{array}{r}4,0 \\
17,6\end{array}$ & $\begin{array}{l}24,8 \\
63,8\end{array}$ & $\begin{array}{r}4,5 \\
23,0\end{array}$ & $\begin{array}{l}22,5 \\
51,2\end{array}$ \\
\hline
\end{tabular}

\section{TABLEAU 12}

Evolution de la taille des adipocytes au cours de la croissance chez le Porc en fonction du type génétique (Wood et al., 1975)

\begin{tabular}{|c|c|c|c|c|}
\hline \multicolumn{5}{|c|}{ Diamètre moyen des adipocytes du lard dorsal } \\
\hline \multirow{2}{*}{$\begin{array}{c}\text { Race } \\
\text { Poids vif }(\mathrm{kg})\end{array}$} & \multicolumn{2}{|c|}{ Large White } & \multicolumn{2}{|c|}{ Piétrain } \\
\hline & 30 & 95 & 30 & 95 \\
\hline $\begin{array}{l}\text { Couche de lard } \\
\qquad \text { externe } \ldots \ldots \ldots \ldots \\
\text { - interne } \ldots \ldots \ldots \ldots\end{array}$ & $\begin{array}{l}68 \\
74\end{array}$ & $\begin{array}{l}74,5 \\
95,5\end{array}$ & $\begin{array}{l}65 \\
64,5\end{array}$ & $\begin{array}{l}81,5 \\
95,0\end{array}$ \\
\hline
\end{tabular}


D’après les résultats évoqués précédemment, il semble que la sélection de porcs à faible prédisposition pour l'engraissement n'a pas eu pour effet de réduire le nombre total d'adipocytes. La sélection en faveur de l'hypermusculature a eu pour conséquence un développement plus faible du tissu adipeux, mais même chez ces animaux de type culard les adipocytes conservent leur capacité d'hypertrophie à un stade tardif de la croissance, donc une certaine propension à l'engraissement.

Par analogie avec les observations de Wood ef al. (1975) concluant à un développement tardif du tissu adipeux chez les porcs de type culard, les travaux de Steele ef al. (1974) aboutissent à des constatations similaires par la mesure de l'activité lipogénique in vitro par cellule (synthèse des acides gras, oxydation en $\mathrm{CO}_{2}$ ). La diminution de cette dernière en fonction de l'âge ne s'observe pas dans les types de porcs à fort développement musculaire. Ceci suppose que le tissu adipeux n'auraił pas atteint son stade de maturité, tant métabolique que morphologique, en relation précisément avec un développement musculaire plus important (Allen et al., 1974, 1975).

Les variations généfiques de la lipolyse chez le porc ont été étudiées par les chercheurs Norvégiens (Trygstad et al., 1972 ; Standal et al., 1973). Ayant trouvé une relation inverse entre l'activité lipolytique du tissu adipeux et le degré d'adiposité chez des animaux ayant subi une sélection contre l'état d'engraissement, ils font l'hypothèse que l'action lipolytique des $\beta$-LPH pourrait être modérée par des substances antagonistes contenues dans le sang et plus particulièrement dans le cas d'animaux de souche grasse. Ils en concluent que la mesure de cette activité antilipolytique pourrait constituer un critère de détection précoce des aptitudes génétiques des porcs pour la production de carcasses maigres.

Dans le même ordre d'idée, dans une étude récente réalisée sur des porcs Large White ef Piétrain d'un poids vif moyen de $50 \mathrm{~kg}$, Gregory ef al. (1976) ont mis en évidence une relation étroite entre le rapport gras sous-cutané/poids du muscle long dorsal, qui constitue un index d'adiposité, et la concentration en insuline plasmatique à jeun $(r=0,98)$. Ces auteurs pensent que la mesure de l'insulinémie pourrait servir de critère pour l'évaluation des caractéristiques de carcasse des porcs à l'abattage, compte tenu du rôle de l'insuline dans la régulation du développement de la masse adipeuse.

En définitive, l'obtention de types de porcs présentant un développement important et précoce du tissu musculaire, grâce à une sélection basée sur des critères zootechniques (vitesse de croissance, efficacité alimentaire, proportion de morceaux maigres dans la carcasse), ne semble pas avoir modifié la capacité du tissu adipeux à se développer à un stade tardif de la croissance, mais simplement l'âge auquel elle se manifeste. A l'inverse, une sélection à rebours en vue de la miniaturisation des animaux, par son effet négatif sur le développement musculaire, a favorisé le dépôt précoce des masses grasses jusqu'au stade de l'obésité. Il s'ensuit que le porc miniature n'est pas un modèle réduit du porc normal et il convient d'en tenir compte lorsqu'on l'utilise comme modèle d'étude en recherche biomédicale.

Dans certains cas, l'intensité accrue de la croissance musculaire a eu pour conséquence une susceptibilité particulière aux stress, associée elle-même à une détérioration de la qualité de la viande à l'abattage. Il n'est pas exclu cependant qu'une sélection efficace contre les composantes métaboliques de l'adiposité, par le choix de critères qu'il reste à préciser, permette de réaliser plus facilement un compromis entre 
l'amélioration des caractéristiques de conformation des carcasses ef le maintien de la qualité des viandes produites.

\section{Variations nutritionnelles.}

2.1. Contrôle quantitatif du niveau d'ingestion. Le comportement boulimique du porc s'accompagne d'une adiposité excessive de sa carcasse, lorsqu'il a un libre accès à une nourriture à forte concentration en énergie. C'est donc par un contrôle quantitatif du niveau d'ingestion énergétique que l'on peut espérer une réduction de l'état d'engraissement des animaux à l'abattage, dès lors qu'il s'agit de combattre un excès d'adiposité par hyperphagie.

Une première possibilité est offerte par le rationnement, c'est-à-dire par un apport quotidien d'aliment ajusté en fonction de l'âge ou du poids vif. L'intensité de la restriction énergétique doit d'ailleurs tenir compte des différences d'aptiłude au rationnement, notamment selon le sexe (Desmoulin, 1969). Ainsi, chez la femelle, une restriction énergétique modérée permet d'améliorer très netfement les caractéristiques de composition corporelle. Chez le castrat, par contre, une réduction sensible de l'état d'adiposité ne peut être obtenue qu'avec un rationnement très sévère pendant la phase de finition et au prix d'une forte augmentation du coût alimentaire. Sur le plan pratique, le rationnement d'un animal naturellement obèse comme le castrat apparaît ainsi comme un pis-aller.

De la même façon, l'intensité du rationnement doit être adaptée en fonction des aptitudes génétiques des animaux. Chez les porcs de type gras, qui présentent un développement précoce du tissu adipeux, il est nécessaire d'intervenir dès la phase initiale de la croissance.

TABLEAU 13

Influence d'une restriction alimentaire précoce $\left(^{1}\right)$ sur le développement ultérieur du tissu adipeux chez le porc. (Lee ef al., 1973a, b)

\begin{tabular}{|c|c|c|c|c|}
\hline $\begin{array}{c}\text { Race } \\
\text { Niveau alimentation }\end{array}$ & $\begin{array}{l}\text { Poland } \\
\text { Témoin }\end{array}$ & $\begin{array}{l}\text { Chind } \\
\text { Restreint }\end{array}$ & Témoin & Restreint \\
\hline \multicolumn{5}{|l|}{ A âge constant (24 sem.) ( $\left.{ }^{2}\right)$} \\
\hline $\begin{array}{l}\text { Nombre d'animaux } \ldots \ldots \ldots \ldots \ldots \ldots \ldots \ldots \\
\text { Gras total }(\mathrm{kg}) \ldots \ldots \ldots \ldots \ldots \ldots \ldots \\
\text { Diamètre moyen des adipocytes }(\mu)\end{array}$ & $\begin{array}{r}4 \\
23\end{array}$ & $\begin{array}{r}3 \\
10\end{array}$ & $\begin{array}{r}3 \\
18\end{array}$ & $\begin{array}{l}4 \\
8,5\end{array}$ \\
\hline $\begin{array}{l}- \text { Gras sous-cutané } \ldots \ldots \ldots \ldots \ldots \ldots \ldots \\
- \text { Gras abdominal } \ldots \ldots \ldots \ldots \ldots \ldots \ldots \\
\text { - Gras intramusculaire } \ldots \ldots \ldots \ldots \ldots\end{array}$ & $\begin{array}{r}119 \\
102 \\
64\end{array}$ & $\begin{array}{l}78 \\
75 \\
51\end{array}$ & $\begin{array}{r}108 \\
89 \\
62\end{array}$ & $\begin{array}{l}85 \\
81 \\
49\end{array}$ \\
\hline $\begin{array}{l}\text { A poids constant }(80 \mathrm{~kg}) \\
\text { Nombre d'animaux } \ldots \ldots \ldots \ldots \ldots \ldots \ldots \ldots \\
\text { Gras total }(\mathrm{kg}) \ldots \ldots \ldots \ldots \ldots \ldots \ldots \ldots \\
\text { Diamètre moyen des adipocytes }(\mu) \ldots \ldots \ldots\end{array}$ & $\begin{array}{r}5 \\
18\end{array}$ & $\begin{array}{c}4 \\
17,5\end{array}$ & $\begin{array}{c}4 \\
18,5\end{array}$ & $\begin{array}{c}4 \\
16,5\end{array}$ \\
\hline $\begin{array}{l}\text { - Gras sous-cutané } \ldots \ldots \ldots \ldots \ldots \ldots \ldots \\
\text { - Gras abdominal } \ldots \ldots \ldots \ldots \ldots \ldots \ldots\end{array}$ & $\begin{array}{r}112 \\
100 \\
64\end{array}$ & $\begin{array}{r}111 \\
97 \\
57\end{array}$ & $\begin{array}{r}118 \\
98 \\
65\end{array}$ & $\begin{array}{r}108 \\
96 \\
58\end{array}$ \\
\hline
\end{tabular}

(1) Pendant la phase d'allaitement (4 sem.), correspondant aux gains respectifs de 20 et $30 \mathrm{~g} / \mathrm{j}$ au cours des deux premières semaines et des deux suivantes.

$\left({ }^{2}\right)$ Poids vif moyen à 24 semaines d'âge : $82 \mathrm{~kg}$ pour les témoins, $53 \mathrm{~kg}$ pour les restreints. 
On serait tenté d'en déduire qu'un rationnement pendant le jeune âge pourrait constituer un moyen de lutte efficace contre les risques d'adiposité excessive au cours des phases ultérieures de la vie de l'animal. En réalité, il semble qu'il n'en soił pas ainsi dans le cas du porc. Contrairement à ce que l'on observe chez le rat (Knittle et Hirsch, 1968), une restriction énergétique très sévère pendant les 4 premières semaines d'allaitement, selon Lee et al. $(1973 a, b)$, ne semble entraîner aucune modification significative du nombre final d'adipocytes dans le tissu adipeux sous-cutané au stade d'abattage (24 semaines d'âge ou $80 \mathrm{~kg}$ ), tandis que la réduction des dépôts gras qui en résulte est accompagnée d'une diminution du diamètre des cellules adipeuses (tabl. 13). Par contre, au niveau du gras intramusculaire, tissu à développement tardif, le nombre total d'adipocytes, tout comme leur taille, est affecté par une restriction alimentaire dès la naissance. De leur côté, Lister et Mc Cance (1967) rapportent qu'une réduction sévère du niveau alimentaire à un stade précoce de la croissance postnatale chez le porc est sans effet sur le nombre d'adipocytes dans les dépôts gras sous-cutanés et viscéraux.

Si l'on considère d'une façon plus particulière l'influence du niveau énergétique de la ration sur l'activité lipogénique du tissu adipeux, les travaux de Sharma et al. (1973) sur des porcelets sevrés à l'âge de trois semaines ont montré que l'élévation du niveau énergétique journalier de 140 à 240 et 340 kcal d'énergie métabolisable $/ \mathrm{kg}^{0.75}$ entraîne une meilleure utilisation in vitro du glucose-U-14C par le tissu adipeux (synthèse des acides gras, oxydation en $\mathrm{CO}_{2}$ ), parallèlement à une augmentation de l'adiposité.

Une deuxième possibilité de réduction de l'adiposité consiste en une limitation de la concentration en énergie du régime, lorsque celui-ci est alllové à volonté. Dans ce cas, c'esł le porc qui règle lui-même son niveau de consommation, la quantité d'énergie disponible étant d'autant plus faible que la concentration dans le régime est moins élevée (Henry, 1969). Dans la mesure où le porc reçoit de plus en plus des aliments à valeur énergétique élevée (comme les céréales), une dilution de l'énergie de la ration est alors obtenue par l'incorporation d'aliments cellulosiques. Mais il en résulte inévitablement un gaspillage de l'énergie disponible, ce qui n'est guère envisageable dans une conjoncture de pénurie de sources énergétiques.

Remarquons toutefois que les possibilités de régulation du niveau d'ingestion alimentaire, chez le porc, sont d'autant meilleures que les aptitudes à la croissance musculaire sont plus fortes, tandis que le comportement hyperphagique est en relation avec l'intensité du développement du tissu adipeux. C'est ainsi que des animaux de type culard (Landrace Belge, Piétrain) peuvent être nourris à volonté, même avec des régimes à concentration élevée en énergie (rations à base de maïs par exemple), tout en produisant des carcasses à faible état d'engraissement (Sellier et al., 1974). En permettant un « autorationnement » dans les conditions de libre consommation, la sélection de porcs à fort développement musculaire présenterait l'avantage d'éviter à terme la pratique du rationnement, qui constitue en définitive un moyen coûteux pour abaisser l'état d'engraissement dans les races à forte adiposité.

2.2. Influence de la nature de l'apport énergétique. Le porc est avant tout un consommateur de glucides, notamment sous forme d'amidon qui constitue un substrat privilégié pour la formation des dépôts gras, principalement par la voie de l' $\alpha$-glycérophosphate, le précurseur du glycérol (O'Hea et Leveille, 1969a). 
Alors que chez le rat l'obésité nutritionnelle est obtenue essentiellement à l'aide des régimes hypergras, chez le porc, en raison de la faible teneur des rations habituelles à base de céréales et de fourteaux dégraissés en lipides (environ 2 p. 100), les graisses exogènes ne constituent qu'une source accessoire de formation des dépôts gras. Quoiqu'il en soit, l'introduction de matières grasses à taux croissant dans la ration du porc provoque une diminution de la lipogenèse in vitro, qu'il s'agisse de l'utilisation du glucose-U-U. C ou des activités des enzymes à NADPH (O'Hea ef Leveille, 1970 ; Allee ef al. $(1971 a, b, c)$, tandis que les animaux sont plus gras (tabl. 14). Sur le plan de la composition en acides gras et du degré d'insaturation, les dépôts adipeux sont alors le reflet des graisses ingérées (Henry, 1972). Selon Allee et al. (1972), la nature des matières grasses ne semble exercer aucune influence spécifique sur l'intensité de la lipogenèse, tout au moins lorsqu'il s'agit d'acides gras à chaîne longue. Sur ce point, le porc se comporte de la même façon que le rat, les acides gras saturés ef insaturés étant également effectifs pour inhiber la synthèse de novo des lipides. Waterman et al. (1975) ont montré cependant que la lipogenèse dans le tissu adipeux du porc est déprimée plus fortement par le suif que par l'huile de carthame, tandis que Mersmann et al. (1976a) n'enregistrent aucun effet dépressif des matières grasses alimentaires sur l'activité lipogénique du tissu adipeux chez le tout jeune porcelet nourri au lait artificiel. On observe par ailleurs une utilisation moindre pour la lipogenèse dans le cas des acides gras à chaîne courte ef moyenne, dontl'oxydation accrue à des fins énergétiques a été dẻmontrée chez le porc dans des essais in vitro (Allee, 1970 ; Allee et al., 1972) et in vivo (Miller et al., 1971). Il y a lieu de noter par ailleurs que l'effet dépressif des lipides sur la lipogenèse s'observe avec la même intensité chez les animaux de types maigre et gras (Allee ef al., 1972).

\section{TABLEAU 14}

Influences respectives des toux de lipides et de proféines du régime sur l'activité lipogénique du tissu adipeux chez le porc en croissance (1) (Allee ef al., 1971c)

\begin{tabular}{|c|c|c|c|c|c|c|}
\hline & \multicolumn{3}{|c|}{ Lipides (p. 100) $\left(^{2}\right)$} & \multicolumn{3}{|c|}{ Protéines (p. 100) $\left({ }^{3}\right)$} \\
\hline & 1 & & 13 & 12 & & 24 \\
\hline $\begin{array}{l}\text { Gain moyen } / \mathrm{j}(\mathrm{g}) \ldots \ldots \ldots \ldots \ldots \ldots \ldots \ldots \ldots \ldots \ldots \\
\text { Ep. lard dorsal }(\mathrm{mm})\end{array}$ & $\begin{array}{r}727 \\
26,9\end{array}$ & * & $\begin{array}{l}816 \\
30,6\end{array}$ & $\begin{array}{l}759 \\
29,5\end{array}$ & $\begin{array}{l}\text { NS } \\
\text { NS }\end{array}$ & $\begin{array}{l}784 \\
27,9\end{array}$ \\
\hline \multicolumn{7}{|l|}{ Utilisation du glucose- $U-{ }^{14} \mathrm{C}$ in vitro $\left(^{4}\right):$} \\
\hline $\begin{array}{l}\text { - incorporation dans les ac. gras } \ldots \ldots \ldots \ldots \ldots \\
\text { - oxydation en } \mathrm{CO}_{2} \ldots \ldots \ldots \ldots \ldots \ldots \ldots \ldots \\
\text { — incorporation dans le glycérol } \ldots \ldots \ldots \ldots \ldots \ldots\end{array}$ & $\begin{array}{r}472 \\
212 \\
76\end{array}$ & $\begin{array}{l}* * \\
* * \\
*\end{array}$ & $\begin{array}{r}172 \\
89 \\
34\end{array}$ & $\begin{array}{r}382 \\
179 \\
61\end{array}$ & $\begin{array}{l}* * \\
* * \\
\text { NS }\end{array}$ & $\begin{array}{r}262 \\
122 \\
49\end{array}$ \\
\hline \multicolumn{7}{|l|}{ Activités enzymatiques $\left({ }^{5}\right)$} \\
\hline 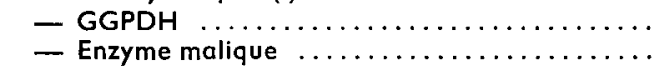 & $\begin{array}{l}99 \\
74\end{array}$ & $\begin{array}{l}\text { NS } \\
* *\end{array}$ & $\begin{array}{l}70 \\
38\end{array}$ & $\begin{array}{l}79 \\
62\end{array}$ & $\begin{array}{l}\text { NS } \\
(0,10)\end{array}$ & $\begin{array}{l}90 \\
51\end{array}$ \\
\hline
\end{tabular}

(1) Entre 46 et $90 \mathrm{~kg}$; 10 animaux par lot. Alimentation selon l'appétit : 2 repas de $60 \mathrm{mn} / \mathrm{j}$. Mesure des activités métaboliques du tissu adipeux, par biopsie du lard dorsal, après 45 jours.

(2) Huile de maïs.

(3) Tourteau de Soja à 50 p. 100 protéines.

(4) $\mathrm{nM}$ substrat $/ 100 \mathrm{mg}$ tissu frais/2 h.

(5) $\mathrm{nM}$ substrat $/ \mathrm{mn} / \mathrm{mg}$ protéines. 
L'élévation du taux de protéines dans la ration, principalement dans les conditions du rationnement, a pour effet de réduire l'état d'engraissement des animaux à l'abattage (Cooke ef al. 1972). Cette action favorable au niveau de la composition corporelle est souvent associée à une diminution de l'intensité de la lipogenèse in vitro, quoique moins forfe que dans le cas des lipides (O'Hea et Leveille, 1970 ; Allee ef al., $1971 c$ : tabl. 14). La réponse à l'augmentation du taux de protéines serait d'ailleurs liée au type génétique : elle serait plus élevée chez les animaux les plus maigres. Comme les lipides, les protéines semblent ainsi avoir un effet propre sur l'activité lipogénique du tissu adipeux du porc, indépendamment de la diminution du taux de glucides qu'elles remplacent. Remarquons cependant que le coûł de plus en plus élevé des protéines alimentaires oblige à limiter leur taux d'introduction dans la ration à un niveau compatible avec l'obtention de carcasses aux qualités recherchées dans les conditions optimales de rentabilité.

2.3. Influence des séquences alimentaires. A la suite des résultats obtenus sur le rat montrant que la multiplication du nombre de repas permet de réduire l'état d'adiposité, on a pensé qu'il pouvait en être de même pour le porc. En fait, chez ce dernier, l'augmentation de la fréquence de distribution des repas au cours du nycthémère est sans effet sur les caractéristiques de composition corporelle à l'abattage (Friend et Cunningham, 1964, 1967), pas plus que sur l'intensité de la lipogenèse du tissu adipeux in vitro (O'Hea ef Leveille, 1969b). Ceci est dô probablement à la lenteur du transit digestif qui ne permettrait pas la mise en place des mécanismes adaptatifs lors de l'alimentation par repas. Bien au contraire, les animaux soumis à un seul repas par jour auraient tendance à être plus maigres que ceux qui en reçoivent plusieurs.

Il est à noter à ce propos que lorsque l'alimentation par repas est programmée sur une période plus longue que le nycthémère (par exemple un repas de $2 \mathrm{~h}$ toutes les $48 \mathrm{~h}$ ), on observe une stimulation de l'activité lipogénique du tissu adipeux par rapport à l'alimentation à volonté (Allee, 1970 ; Allee et al., 1971d ; tabl. 15). Dans ces

\section{TABLEAU 15}

Influence de l'alimentation par repas sur la composition corporelle ef les activités méfaboliques du tissu adipeux chez le porc $\left(^{1}\right)($ Allee, 1970)

\begin{tabular}{|c|c|c|c|}
\hline Périodicité du repas & A volonté & $2 \mathrm{~h} / 24 \mathrm{~h}$ & $2 \mathrm{~h} / 48 \mathrm{~h}$ \\
\hline 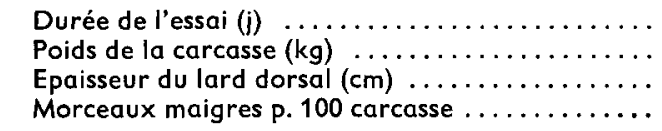 & $\begin{array}{l}60 \\
61,5 \pm 1,1 \\
2,82 \pm 0,08 \\
58,8 \pm 0,9\end{array}$ & $\begin{array}{l}\quad 60 \\
59,1 \pm 1,4 \\
2,36 \pm 0,13 \\
58,0 \pm 0,8\end{array}$ & $\begin{array}{l}\quad 87 \\
54,2 \pm 2,6 \\
1,78 \pm 0,13 \\
61,3 \pm 1,0\end{array}$ \\
\hline \multicolumn{4}{|l|}{ Utilisation du glucose- $U-{ }^{14} \mathrm{C}$ in vitro $\left({ }^{2}\right)$} \\
\hline $\begin{array}{l}\text { Incorporation dans les acides gras } n M / 100 \mathrm{~g} \text { tissu } \\
\text { frais } / 2 \mathrm{~h} \quad \ldots \ldots \ldots \ldots \ldots \ldots \ldots \ldots \ldots \ldots \ldots\end{array}$ & $198 \pm 18$ & $383 \pm 33$ & $551 \pm 61$ \\
\hline Oxydation en $\mathrm{CO}_{2}, \mathrm{nM} / 100 \mathrm{mg}$ tissu frais $/ 2 \mathrm{~h} \ldots \ldots$ & $111 \pm 10$ & $183 \pm 17$ & $247 \pm 32$ \\
\hline \multicolumn{4}{|l|}{ Activité enzyme molique } \\
\hline $\mathrm{nM}$ substrat $/ \mathrm{mn} / \mathrm{mg}$ protéines $\left({ }^{2}\right) \ldots \ldots \ldots \ldots \ldots$ & $107 \pm 9$ & $129 \pm 14$ & $261 \pm 35$ \\
\hline
\end{tabular}

(1) Porcs Yorkshire d'un poids initial de $22 \mathrm{~kg}$; 5 animaux par lot.

(2) Prélèvement de lard dorsal par biopsie après 60 j d'expérience, 7 h après le début du repas. 
conditions, l'état hyperlipogénique peut être atteint, même chez le porc, lorsqu'on limite le temps d'accès à la nourriture, mais seulement sur une période suffisamment longue. Corrélativement, O'Hea et Leveille (1970) enregistrent une variation de l'insulinémie au cours d'une séquence jeûne-alimentation. Ceci nous montre en définitive que les résultats fournis par le rat dans ce domaine ne sont pas forcément transposables aux autres espèces, voire même à l'homme.

La stimulation de l'activité lipolytique du tissu adipeux par voie nutritionnelle peut être obtenue par l'utilisation des propriétés pharmacologiques des substances du groupe des méthylxanthines (théophylline, caféine ...), qui exercent une action inhibitrice sur l'activité de la phosphodiestérase. Une administration orale de caféine (Cunningham, 1968, 1971) ou de théophylline (Cunningham et Friend, 1971) entraîne effectivement chez le porc une accélération de la mobilisation des lipides, accompagnée d'une réduction de l'état d'engraissement au profit de la rétention azotée.

\section{Influence du mode d'élevage.}

3.1. Sevrage précoce ef développement ulférieur du tissu adipeux. Le changement de régime alimentaire au moment du sevrage, caractérisé par le passage d'un régime lacté, riche en lipides, à un régime riche en glucides, se traduit par une forte augmentation des activités des enzymes de la lipogenèse (Anderson et Kauffman, 1973 ; Mersmann ef al., 1973a ; Lee et Kauffman, 1974 a), de même que par une incorporation accrue du glucose et d'acétate marqués dans les coupes de tissu adipeux in vitro (Mersmann et al., 1973a). Ces résultats sont en accord avec ceux enregistrés antérieurement dans les mêmes conditions chez le rat (Ballard et Hanson, 1967).

Selon Mersmann ef al. (1973c), le degré d'adaptation des porcelets au régime glucidique, au moment du sevrage, ne dépend pas seulement des proportions relatives de glucides el de lipides, mais aussi de l'âge au sevrage. Ainsi, le taux d'incorporation du glucose dans les lipides ou le $\mathrm{CO}_{2}$ augmente fortement dans le cas d'un sevrage à 21 ou 35 jours, mais faiblement s'il s'agit d'un sevrage un peu plus précoce à 14 jours. Alors que chez les porcelets non sevrés, 50 p. $100 \mathrm{du}$ glucose sont incorporés dans le glycérol, le sevrage à 21 ou 35 jours fait baisser ce taux d'incorporation à moins de 30 p. 100.

De la même façon, dans une étude récente de Mersmann et al. (1975c), un sevrage à 19 jours entraîne une diminution de l'activité lipolytique du tissu adipeux mesurée in vitro en présence d'adrénaline, indépendamment du rapport lipides/glucides du régime alimentaire. L'effet dépressif ainsi observé au niveau de la lipolyse pourrait résulter du stress subi au moment du sevrage, ce qui aurait pour conséquence une altération de la capacité de mobilisation des acides gras. On peut rapprocher de cette hypothèse l'observation de Stanton et al. (1972) montrant que des manipulations répétées des animaux ou une exposition intermittente au froid provoquent un épuisement des surrénales en catécholamines.

En dehors de ces effets à court terme sur le métabolisme du tissu adipeux (lipogenèse, lipolyse), le sevrage peut avoir des conséquences sur les performances ultérieures de croissance et les caractéristiques finales des carcasses à l'abattage (Henry, 1966 ; Nielsen, 1973).

Dans l'état actuel de nos connaissances dans ce domaine, si les besoins nutrition- 
nels du porcelet sont normalement couverts, il n'y a pas lieu de penser que le sevrage précoce en lui-même affecte la capacité ultérieure de production de viande maigre.

3.2. Suppression de la castration. La castration précoce des porcs mâles, si elle est nécessaire pour éviłer l'apparition d'anomalies d'odeurs sexuelles dans la viande, n'en constitue pas moins une pratique fort coûteuse, puisqu'elle se traduit, par une perte de rendement en viande maigre de l'ordre de 10 p. 100 et un accroissement du coût alimentaire de 12 p. 100 (Desmoulin, 1972).

Ce n'est donc pas sans raison que la production de viande de porc mâle entier a été envisagée. Le développement d'une telle technique, qui permet de tirer le plus grand parti des capacités anabolisantes du mâle entier, est cependant limité par la mise au point de tests suffisamment précis pour juger les défauts d'odeurs sexuelles lors de la cuisson des viandes et décider de leur destination vers la consommation en frais ou la transformation.

3.3. Influence du milieu d'élevage. Par leurs effets sur les échanges thermiques, l'activité physique ef le niveau spontané d'ingestion de nourriture, les facteurs d'environnement, et principalement la température ambiante, sont susceptibles de modifier plus ou moins fortement les performances de croissance du porc, et par voie de conséquence l'état d'engraissement des animaux à l'abattage. En dehors des variations de la composition des dépôts, dont il a été fait état dans une revue antérieure (Henry, 1972), ceci peut avoir des répercussions au niveau des activités métaboliques du tissu adipeux, en particulier les processus de lipolyse.

Une exposition prolongée des porcs au froid, en dessous de la température critique, se traduit, après une phase d'adaptation, par une réduction de la thermolyse et une activation de la thermogenèse, accompagnée d'une augmentation de la consommation spontanée d'aliment, ce qui signifie une part accrue du métabolisme oxydatif au détriment de l'anabolisme. En dépit des résultats divergents observés au niveau de la composition corporelle, suivant que les animaux sont nourris à volonté ou soumis à un même plan de rationnement en fonction du poids vif, on peut considérer, avec Fuller et Boyne $(1971,1972)$, que les effets dépressifs du froid et de l'abaissement du niveau d'alimentation sur le gain moyen journalier et la rétention azotée sont pratiquement additifs, et que pour un même niveau d'ingestion l'influence de la température ne fait apparaître aucune différence apparente dans le degré d'adiposité des carcasses à l'abattage.

Au plan métabolique, l'effet du froid, comme celui du jeûne, se manifeste avant tout par une stimulation de la lipolyse (teneur accrue en acides gras libres du sang) par la voie des catécholamines, agissant au niveau des récepteurs $\beta$-adrénergiques, tandis que l'on observe, notamment chez le jeûne, une diminution du quotient respiratoire (Curtis et al., 1970 ; Marple et al., 1972). Les capacités de résistance au froid sont d'ailleurs sous la dépendance de l'origine génétique. Ainsi, la comparaison du sanglier et du porc domestique, pendant la période périnatale, fait apparaître chez le premier une tolérance au froid supérieure (Foley ef al., 1971) et une réponse lipolytique accrue à une injection de noradrénaline (Horn ef al., 1973). Mais les éfudes 
histologiques pratiquées à ce stade n'ont pas permis de mettre en évidence la présence de tissu adipeux brun chez le marcassin.

Par ailleurs, l'élévation de la température ambiante au delà de la zone de thermorégulation provoque, à l'issue d'une période d'adaptation, une augmentation de la thermolyse ef une diminution de la thermogenèse, qui est en relation avec un hypofonctionnement thyroïdien ef entraîne à son tour une baisse de la consommation spontanée d'aliment. Comme sous l'effet du froid, on observe une élévation du taux d'acides gras libres sanguins (Marple ef al., 1972 ; Hsia, 1974), mais par un mécanisme différent, vraisemblablement par l'intermédiaire d'une stimulation de la sécrétion d'ACTH ou d'hormone de croissance, dont on connaît les propriétés lipolytiques. Comme le soulignent Marple ef al. (1972), l'effet de la température est accentué en présence d'une hygrométrie élevée, tandis que les variations enregistrées dans la résistance ou la susceptibilité au stress thermique font ressortir des différences plus ou moins marquées selon le type génétique.

L'influence des autres facteurs de milieu sur les performances de croissance et le développement du tissu adipeux, chez le porc, a été jusqu'à présent très peu étudiée. Il en est ainsi de l'intensité et du rythme d'éclairement. Les observations effectuées sur des animaux soumis à un éclairement normal ou à l'obscurité complète (ce qui a pour avantage de favoriser leur tranquillité) n'ont pas permis dans l'ensemble de dégager des différences notables dans la vitesse de croissance, l'efficacité alimentaire ou la composition corporelle (Braude ef al., 1958 ; Pfeiffer, 1968 ; Blödow et al., 1969).

D'une façon plus générale, le développement des systèmes d'élevage intensif en confinement peut avoir une incidence défavorable sur les performances de croissance et l'état d'engraissement, ne serait-ce que par l'intermédiaire des stress répétés subis par les animaux et de leurs répercussions sur l'activité lipolytique. Au plan métabolique, nous avons fait état précédemment d'une étude de Stanton ef al. (1972) montrant que des manipulations répétées des animaux, comme une exposition intermittente au froid, au cours de la phase critique des premiers jours de vie du porcelet, provoque un épuisement des surrénales en catécholamines.

En conclusion, les différents types de porcs exploités pour la production de viande, en France comme dans les autres pays, se sont considérablement diversifiés au cours des dernières décades, en particulier grâce aux efforts de la sélection. Une meilleure connaissance des mécanismes impliqués dans le développement, tant morphologique que métabolique du tissu adipeux, devrait permettre, par le choix de critères de sélection appropriés et en corrigeant cerłaines insuffisances des techniques d'élevage et d'alimentation, de progresser plus efficacement dans la voie de l'amélioration de la production de viande maigre, tout en tenant compte des contraintes liées à la qualité.

Réunion Groupe Développement INRA/Productions animales Thiverval-Grignon, 14-15 avril 1976.

\section{Références}

ALLEE G. L., 1970. Effect of dietary protein and fat, age and periodicity. Thèse, Univ. Illinois, UrbanaChampaign.

ALLEE G. L., BAKER D. H., LEVEILLE G. A., 1971a. Fat utilization and lipogenesis in the young pig. J. Nutr., 101, 1415-1421. 
ALLEE G. L., BAKER D. H., LEVEILLE G. A., 1971b. Influence of level of dietary fat on adipose tissue lipogenesis and enzymatic activity in the pig. J. anim. Sci., 33, 1248-1254.

ALLEE G. L., O'HEA E. K., LEVEILLE G. A., BAKER D. H., 1971c. Influence of dietary protein and fat on lipogenesis and enzymatic activity in pig adipose tissue. J. Nutr., 101, 869-878.

ALLEE G. L., ROMSOS D. R., LEVEILLE G. A., BAKER D. H., 1971d. Metabolic adaptations induced by meal-eating in the pig. J. anim. Sci., 33, 226 (abstr.).

ALLEE G. L., ROMSOS D. R., LEVEILLE G. A., BAKER D. H., 1972. Lipogenesis and enzymatic activity in pig adipose tissue as influenced by source of dietary fat. J. anim. Sci., 35, 41-47.

ALLEN C. E., 1976. Cellularity of adipose tissue in meat animals. Fed. Proc., 35, 2302-2307.

ALLEN C. E., BEITZ D. C., CRAMER D. A., KAUFFMAN R. G., 1976. Biology of fat in meat animals, 76 p. North-Central Res. Pub. No 234, Univ. Wisconsin-Madison.

ALLEN C. E., HEGARTY P. V. J., ETHERTON T. D., ABERLE E. D., 1975. Biological interaction of muscle and adipose tissues. 28th Annual Reciprocal Meat Conf. Amer. Meat Sci. Assoc., 202-213, Nat. Livestock and Meat Board, Chicago (ILL).

ALLEN C. E., THOMPSON E. H., HEGARTY P. V. J., 1974. Physiological maturity of muscle and adipose cells in meat animals. Proc. 27th Annual Reciprocal Meat Conf. Amer. Meat Sci. Assoc., 8-27, Nat. Livestock and Meat Board, Chicago (ILL).

ANDERSON D. B., 1971. Cellular and enzymatic changes in porcine adipose tissue during growth. Thèse, Univ. Wisconsin.

ANDERSON D. B., KAUFFMAN R. G., 1973a. Cellular and enzymatic changes in porcine adipose tissue during growth. J. Lipid Res., 14, 160-168.

ANDERSON D. B., KAUFFMAN R. G., 1973b. Metabolism of developing adipose tissue in the pig. Nutr. Rev., 31, 257-259.

ANDERSON D. B., KAUFFMAN R. G., KASTENSCHMIDT L. L., 1972. Lipogenic enzyme activities and cellularity of porcine adipose tissue from various anatomical locations. J. Lipid Res., 13, 593-599.

AUFFRAY P., 1975. Regulation of feed intake in the pig. Neurophysiological aspects and feeding pattern. $26^{\mathrm{e}}$ réunion annuelle Commission Porcine F. E. Z. Varsovie.

BALLARD F. J., HANSON R. W., 1967. Changes in lipid synthesis in rat liver during development. Biochem. J., 102, 952-958.

BLÖDOW G., KIRMSE K., OTTO E., PÜSCHEL F., SCHLISSKE W., STEGER H., ZAREND W., 1969. Untersuchungen zur Hell- und Dunkelstallhaltung von Mastschweinen. Archiv. Tierz., 12, 259-272.

BRAUDE R., MITCHELL K. G., KELSEY P. F., OWEN V. M., 1958. The effect of light on fattening pigs Proc. Nutr. Soc., 17, 38-39. (abstr.).

BRAY G. A., LUONG D., YORK D. A., 1974. Regulation of adipose tissue mass in genetically obese rodents. In VAGUE J., BOYER J. The regulation of the adipose tissue mass, vol. 3, 111-121. Excerpta medica, Amsterdam.

BUZZELL B. L., MERKEL R. A., ROMSOS D. R., MILLER E. R., 1975. Lipolytic activity of two porcine GH'S in vivo. J. anim. Sci., 41, 287 (abstr.).

CALLOW E. H., 1947. Comparative studies of meat. I. The chemical composition of fatty and muscular tissue in relation to growth and fattening. J. agric. Sci., 37, 113-131.

CALLOW E. H., 1948. Comparative studies of meat. Il. The changes in the carcass during growth and fattening, and their relation to the chemical composition of the fatty and muscular tissues. J. agric. Sci., 38, 174-199.

COOKE R., LODGE G. A., LEWIS D., 1972. Influence of energy and protein concentration in the diet on the performance of growing pigs. I. Response to protein intake on a high-energy diet. Anim. Prod., 14, 35-46.

CUNNINGHAM H. M., 1968. Effect of caffeine on nitrogen retention, carcass composition, fat mobilization and oxidation of ${ }^{14} \mathrm{C}$ labeled body fat in pigs. J. anim. Sci. 27, 424-430.

CUNNINGHAM H. M., 1971. Conversion of body fat and protein to energy and the transfer of carbon from fatty acids to glucose in the growing pig. Can. J. anim. Sci., 51, 341-350.

CUNNINGHAM H. M., FRIEND, D. W., 1965. Influence of epinephrine, norepinephrine and nicotin on bloods levels of glucose free fatty acids and amino nitrogen in pigs. J. onim. Sci., 24, 41.-46.

CUNNINGHAM H. M., FRIEND D. W., 1971. Effect of theophylline on the mobilization and oxidation of body fat and the carcass quality of pigs. Can. J. anim. Sci., 51, 639-643. 
CURTIS S. E., CHRISTISON G. I., ROBERTSON W. D., 1970. Effects of acute cold exposure and age on respiratory quotients in piglets. Proc. Soc. exp. Biol. Med. 134, 188-191.

DEB S., HERBEIN J. H., MARTIN R. J., 1973. Adipose cell size and lipid metabolism Fed. Prod., 32, 940 (abstr.).

DESMOULIN B., 1969. Influence de l'alimentation restreinte sur les performances du porc : variation suivant le sexe. Journées Rech. Porcine, I. N. R. A., 67-72.

DESMOULIN B., 1971. Le rationnement collectif des porcs suivant le sexe et les conditions d'environnement. Ann. Zootech., 20, 509-520.

DESMOULIN B., 1972. Influence de la castration et du stade d'abattage du porc mâle sur la constitution des graisses de dépôts ef leurs anomalies d'odeur. Rev. franç. Corps gras, $\mathrm{n}^{\circ}$ 7, 437-445.

DESMOULIN B., BONNEAU M., BOURDON D., 1974. Etude en bilan azoté ef composition corporelle des porcs mâles entiers ou castrés de race Large White. Journées Rech. porcine en France, I.N.R.A.-I.T.P. éd., 247-255.

DESMOULIN B., POMMERET P., 1974. Références de composition anatomique et critères de classification des carcasses de porcs femelles de type Landrace Français, Landrace Belge et Piétrain. Journées Rech. Porcine en France, I.N.R.A.-I.T.P., éd., 221-232.

DESMOULIN B., POMMERET P., 1975. Evolution de la composition anatomique des porcs femelles des types Landrace Français, Landrace Belge ef Piétrain. Conséquences sur les méthodes d'orientation des productions. Journées Rech. Porcine en France, I.N.R.A.-I.T.P., éd. 179-195.

DESNOYERS F., VODOVAR N., 1974. Apparition, origine et évolution des tissus adipeux épididymaire et péricardique du fœus de porc. Ann. Biol. anim. Bioch. Biophys., 14, 769-780.

DESRANLEAU R., GILARDEAU C., CHRETIEN M., 1972. Radioimmunoassay of ovine Beta-Lipotropic Hormone. Endocrinology, 91, 1004-1009.

ENSER M. B., MacFIE H. J., MOODY W. B., RESTALL D. J., WOOD J. D., 1976a. The growth and cellularity of pig backfats. Anim. Prod. 22, 151 (abstr.).

ENSER M. B., WOOD J.D., RESTALLD. J., MacFIE H.J. H., 1976b. The cellularity of adipose tissue from pigs of different weights. J. agric. Sci., 86, 633-638.

FOLEY C. W., SEERLEY R. W., HANSEN W. J., CURTIS S. E., 1971. Thermoregulatory responses to cold environment by neonatal wild and domestic piglets. J. anim. Sci., 32, 926-929.

FRIEND D. W., CUNNINGHAM H. M., 1964. Effect of feeding frequency on metabolism, rate and efficiency of gain and on carcass quality of pigs. J. Nutr., 83, 251-256.

FRIEND D. W., CUNNINGHAM H. M., 1967. Growth, carcass, blood and fat studies with pigs fed once or five times daily. J. anim. Sci., 26, 316-322.

FULLER M. F., BOYNE A. W., 1971. The effects of environmental temperature on the growth and metabolism of pigs given different amounts of food. I. Nitrogen metabolism, growth and body composition. Br.J. Nutr., 25, 259-272.

FULLER M. F., BOYNE A. W., 1972. The effects of environmental temperature on the growth and metabolism of pigs given different amounts of food. Il. Energy metabolism. Br. J. Nufr., 28, 373-384.

GOULD K. K., CARLSON A. J., 1911. Further studies on the relation of the pancreas to the serum and lymph diastases. Am. J. Physiol., 29, 165-181.

GREGORY N. G., WOOD J. D., LISTER D., 1976. Studies of the role of plasma insulin in controlling body composition and meat qualities in pigs. Anim. Prod., 22, 150-151 (abstr.).

HENRY Y., 1966. Relations entre sevrage et performances ultérieures chez le Porc. Bull. Tech. Inf., 209, 401-414.

HENRY Y., 1969. Effets nutritionnels de l'incorporation de cellulose purifiée dans le régime du porc en croissance finition. II. Influence sur les performances de croissance ef la composition corporelle. Ann. Zootech., 18, 371-384.

HENRY Y., 1972. Facteurs de variation de la composition des dépôts adipeux chez le porc. Rev. franç. Corps gras, no 6, 367-376.

HENRY Y., 1975. L'obésité chez le porc : comment la maîtriser. Économie ef Médecine Animales, 16, 261-283

HERTELENDY F., MACHLIN L. J., GORDON R. S., HORINO M., KIPNIS D. M., 1966. Lipolytic activity and inhibition of insulin release by epinephrine in the pig. Proc. Soc. exp. Biol. Med., 121, 675-677 
HOFFMEISTER H. G., SINK J. D., 1974. Cellularity of porcine adipose tissue during growth. Proc. Pa Acad. Sci., 48, 142-145.

HOOD R. L., 1972. Adipose tissue cellularity and lipogenic activity in porcine and bovine animals. Thèse, Univ. Minnesota, 298 p.

HOOD R. L., ALLEN D. E., 1973. Lipogenic enzyme activity in adipose tissue during the growth of swine with different propensities to fatten. J. Nutr., 103, 353-362.

HOOD R. L., ALLEN D. E., 1977. Cellularity of porcine adipose tissue : effects of growth and adiposity. J. Lipid Res., 18, 275-284.

HORN G. W., FOLEY C. W., SEERLEY R. W., MUNNELL J. F., 1973. Role of adipose tissue lipolysis in postnatal amelioration of thermogenesis in domestic and wild piglets. J. anim. Sci., 37, 1356-1361.

HSIA L. C., 1974. Acclimatisation of pigs to high temperature. Thèse, Univ. Aberdeen, $56 \mathrm{p}$.

JACOBSON B., SMITH U., 1972. Effect of cell size on lipolysis and antilipolytic action of insulin in human fat cells. J. Lipid Res., 13, 651-656.

KNITTLE J. L., HIRSH J., 1968. Effect of early nutrition on the development of rat epididymal fat pads : cellularity and metabolism. J. clin. Invest., 47, 2091-2098.

LAWRIE R. A., 1966. Meat Science, Pergamon Press Lłd.

LEE Y. B., KAUFFMAN R. G., 1974a. Cellular and enzymatic changes with animal growth in porcine intramuscular adipose tissue. J. anim Sci., 38, 532-537.

LEE Y. B., KAUFFMAN R. G., 1974b. Cellularity and lipogenic enzyme activities of porcine intramuscular adipose tissue. J. anim. Sci., 38, 538-544.

LEE Y. B., KAUFFMAN R. G., GRUMMER R. H., 1973a. Effect of early nutrition on the development of adipose tissue in the pig. I. Age constant basis. J. anim. Sci., 37, 1312-1318.

LEE Y. B., KAUFFMAN R. G., GRUMMER R. H., 1973b. Effect of early nutrition on the development of adipose tissue the pig. Il. Weight constant basis. J. anim. Sci., 37, 1319-1325.

LEVEILLE G. A., ROMSOS D. R., YEH Y., O'HEA E. K., 1975. Lipid biosynthesis in the chick. A consideration of site of synthesis, influence of diet and possible regulatory mechanism. Poultry Sci., 54, 1075-1093.

LISTER D., MCCANCE R. A., 1967. Severe undernutrition in growing and adult animals. 17. The ultimate results of rehabilitation : pigs. Br. J. Nutr., 21, 787-799.

LUKENS F. D. W., 1937. Pancreatectomy in the pig. Am. J. Physiol., 118, 321-327.

MACHLIN L. J., HORINO M., KERTE-LENDY F., KIPNIS D. M., 1968. Plasma growth hormone and insulin levels in the pig. Endocrinology, 82, 369-376.

MARPLE D. N., ABERLE E. D., FORREST J. C., BLAKE W. H., JUDGE M. D., 1972. Endocrine responses of stress susceptible and stress resistant swine to environmental stessors. J. anim. Sci., 35, 576-579.

MARTIN R. J., HERBEIN J. H., 1976. A comparison of the enzyme levels and the in vitro utilization of various substrates for lipogenesis in pair-fed lean and obese pigs. Proc. Soc. expl. Biol. Med., 151, 231-235.

MARTIN R. H., GOBBLE J. L., HARTSOCK T. H., GRAVES H. B., ZIEGLER J. H., 1973. Characterization of an obese syndrome in the pig. Proc. Soc. expl. Biol. Med., 143, 198-203.

MERSMANN H. J., HOUK J. M., PHINNEY G., UNDERWOOD M. C., BROWN L. J., 1973a. Lipogenesis by in vitro liver and adipose tissue preparations from neonatal swine. Amer. J. Physiol., 224, 1123-1129.

MERSMANN H. J., UNDERWOOD M. C., BROWN L. J., HOUK J. M., 1973b. Adipose tissue composition and lipogenic capacity in developing swine. Amer. J. Physiol., 224, 1130-1135.

MERSMANN H. J., HOUK J. M., PHINNEY G., UNDERWOOD M. C., 1973c. Effect of diet and weaning age on in vitro lipogenesis in young swine. J. Nutr., 103, 821-828.

MERSMANN H. J., BROWN L. J., UNDERWOOD M. C., STANTON H. C., 1974. Catecholamineinduced lipolysis in swine. Comp. Biochem. Physiol., 47B, 263-270.

MERSMANN H. J., GOODMAN J. R., BROWN L. J., 1975a. Development of swine adipose tissue morphology and chemical composition. J. Lipid Res., 16, 269-279.

MERSMANN H. J., PHINNEY G., BROWN L. J., 1975b. Ontogeny of epinephrine-induced lipolysis in adipose tissue from swine (Sus domesticus). Gen. Pharmac., 6, 187-191.

MERSMANN H. J., PHINNEY G., BROWN L. J., 1975c. Influence of weaning on swine adipose tissue lipolysis. J. anim. Sci., 41, 1048-1052. 
MERSMANN H. J., ALLEN C. E., STEFFEN D. G., BROWN L. G., DANIELSON D. M., 1976a. Effect of age, weaning and diet on swine adipose tissue and liver lipogenesis J. anim. Sci., 43, 140150.

MERSMANN H. J., BROWN L. J., BEUVING R. De M., ARAKELIAN M. C., 1976b. Lipolytic activity of swine adipocytes. Amer. J. Physiol., 230, 1439-1443.

MILLER G. M., CONRAD J. H., KEEMAN T. W., FEATHERSTON W. R., 1971. Fatty acid oxidation in young pigs. J. Nutr., 101, 1343-1349.

MOODY W. G., ENSER M. B., WOOD J. D., RESTALL D. H., LISTER D., 1975a. Comparison of fat and muscle development in Piétrain and Large White pigs. J. anim. Sci., 41, 299 (abstr.).

MOODY W. G., VOYLE C., LISTER D., 1975b. Morphology and ultrastructure of subcutaneous fat in Piétrain and Large White pigs. J. anim. Sci., 41, 299-300 (abstr.).

NIELSEN H. E., 1973. Growth and development in pigs in the pre and postnatal period with special reference to later growth and carcass composition. Berefning Forsogslab., $\mathrm{n}^{\circ} 405,152 \mathrm{p}$.

O'HEA E., 1969. Lipogenesis and aspects of its regulation in the liver and adipose tissue of the chicken and pig. Thèse, Univ. Illinois, $134 \mathrm{p}$.

O'HEA E. K., LEVEILLE G. A., 1968. Lipid metabolism in isolated adipose tissue of the domestic pig (Sus domesticus). Comp. Bioch. Physiol., 26, 1081-1089.

O'HEA E. K., LEVEILLE G. A., 1969a. Significance of adipose tissue and liver as sites of fatty acid synthesis in the pig and the efficiency of utilization of various substrates for lipogenesis. J. Nutr., 99, 338-344.

O'HEA E. K., LEVEILLE G. A., 1969b. Influence of fasting and refeeding on lipogenesis and enzymatic activity of pig adipose tissue. J. Nutr., 99, 345-352.

O'HEA E. K., LEVEILLE G. A., 1970. Studies on the response of pig adipose tissue to insulin. Int. J. Biochem., 1, 605-611.

OSLAGE H. J., FLIEGEL H., 1965. Nitrogen and energy metabolism of growing-fattening pigs with an approximately maximal feed intake. In BLAXTER K. L. Energy metabolism, 297-306. Acad. Press, London.

PERET J., CHANEZ M., COTA J., MACAIRE I., 1975. Effects of quantity and quality of dietary protein and variation in certain enzyme activities on glucose metabolism in the rat. J. Nutr., 105, 1525-1534.

PERSSON B., GENTZ J., HAKKARAINEN J., KELLUM M., 1971. Catecholamine- induced lipolysis and its relation to oxygen consumption in the newborn pig. Pediat. Res. 5, 435-445.

PFEIFFER H., 1968. Die quantitative und qualitative Schlachtkörperzusammensetzung sowie der Nährstoffansatz bei Schweinen unter verschiedenen Haltungsbedingungen. Kühn. Archiv., 82, 1-68.

ROGDAKIS E., 1973. Untersuchungen über die Beziehungen zwischen der Aktivität der NADabhängigen Dehydrogenasen im Fettgewebe und dem Fettansatz beim Schwein. Züchtungskunde, 45, 412-420.

ROGDAKIS E., 1974a. Untersuchungen über die Aktivität NADPH-liefernder Enzyme im Fettgewebe des Schweines. I. Biopsietechnik und Enzymteste sowie enzymatische Unterschiede zwischen verschiedenen anatomischen Stellen des Fettgewebes. Z. Tierphysiol. Tierernähr. Futtermittelkd., 33, 329-338.

ROGDAKIS E., 1974b. Untersuchungen über die Aktivität NADPH-liefernder Enzyme im Fettgewebe des Schweines. II. Vergleich der Enzymaktivitäten von Fett, Leber-und Muskelgewebe sowie der Einfluss des Masłgewichtes, des Fastens, der Wiederfütterung und des Geschlechtes auf die Enzymaktivitäten im Fettgewebe. Z. Tierphysiol. Tierernähr. Futtermittelkd., 34, 77-85.

ROGDAKIS E., 1975. Untersuchungen über die Akfivität NADPH-liefernder Enzyme im Fettgewebe des Schweines. III. Zusammenhänge zwischen Enzymaktivitäten und Verfettungsgrad. $Z$. Tierernährg. Futfermittelkd., 34, 300-311.

RUDMAN D., Di GIROLAMO M., 1967. Comparative studies on the physiology of adipose tissue. Adv. Lipid Res., 5, 35-117.

SCHÖN I., 1973. Improvement of market transparency in meat trade. World Rev. anim. Prod., 9, 34-47.

SCHWANDT P., DOERR H. W., KRONE W., 1971. Enzymaktivitäten in Fettgewebe. Vergleichende Untersuchungen bei Ratte, Schwein und Mensch. Klin. wochenschr., 49, 358-360. 
SCHWANDT P., WEISWEILLER I., RUSCHEWSKI H., HAGEN R., 1973. Lipotropic peptides A and B from pituitary glands. In VAGUE J. BOYER J., The regulation of adipose tissue mass, 103-106, Excerpta Medica, Amsterdam.

SELLIER P., HOUIX Y., DESMOULIN B., HENRY Y., 1974. Premières observations sur la relation entre conditions nutritionnelles et type génétique chez des porcs femelles. Journées Rech. Porcine en France. I.N.R.A., I.T.P. édit., Paris, 209-219.

SHARMA V. D., YOUNG L. G., SMITH G. C. I., SAISON R., 1973. Effects of crossbreeding and sex on energy requirements and utilization by young pigs. Can. J. anim. Sci., 52, 751-759.

SINK J. D., WATKINS J. L., ZIEGLER J. H., MILLER R. C., 1964. Analysis of fat deposition in swine by gas-liquid chromatography. J. anim. Sci., 23, 121-125.

STANDAL N., VOLD E., TRYGSTAD O., FOSS I., 1973. Lipid mobilization in pigs selected for leanness or fatness. Anim. Prod., 16, 37-42.

STANTON H. C., MUELLER R. L., 1973a. Metabolic responses induced in neonatal swine by norepinephrine, epinephrine, and isoproterenol. Proc. Soc. exp., Biol. Med., 143, $492-494$.

STANTON H. C., MUELLER R. L., 1973b. Metabolic responses to cold and catecholamines as a function of age in swine (Sus domesticus). Comp. Biochem. Physiol., 45 A, 215-225.

STANTON H. C., MUELLER R. L., BAILEY C. L., 1972. Adrenal catecholamine levels and synthetizing enzyme activities in newborn swine exposed to cold and 6-hydroxydopamine. Proc. Soc. exp. Biol. Med., 141, 991-995.

STEELE N. C., 1973. Lipogenesis and cellularity of adipose fissue from lean and obese swine. Thèse, Univ. Maryland.

STEELE N. C., FROBISH L. T., KEENEY M., 1974. Adiposity and metabolic activity in adipose tissue of swine selected for backfat thickness : age constant. J. anim. Sci., 37, 367 (abstr.).

TAMASI G., DSEH G., GRAF L., 1969. Effect of porcine $\beta$-lipotropic hormone on lipid metabolism. Experientia, 25, 360-361.

TRYGSTAD O., FOSS I., VOLD E., STANDAL N., 1972. Suppressed lipolysis in genetically fat pigs FEBS Letters, 26, 311-314.

VODOVAR N., DESNOYERS F., FRANCOIS A. C., 1971. Origine et évolution des adipocytes mésentériques du porcelet avant la naissance. J. Microscopie, 11, 265-284.

WANGSNESS P. J., MARTIN R. J., 1975. Insulin secretion in lean and obese pigs. J. anim. Sci., 41, 384 (abstr.).

WATERMAN R. A., ROMSOS D. R., TSAI A. C., MILLER E. R., LEVEILLE G. A., 1975. Influence of dietary safflower oil and tallow on growth, plasma lipids and lipogenesis in rats, pigs and chicks. Proc. Soc. exp., Biol. Med., 150, 347-351.

WEISENBURG C. L., ALLEN C. E., 1973. Adipose tissue metabolism in obese and lean pigs. J. anim. Sci., 17, 293 (abstr.).

WIERZUCHOWSKI M., LING S. M., 1925. Animal calorimetry. On fat production in a young hog. J. biol. Chem., 64, 697-707.

WOLFE R. G., MAXWELL C. V., NELSON E. C., JOHNSON R. R., 1973. Effect of dietary fat level on performance and lipogenesis in the neonatal pig. J. anim. Sci., 37, 293 (abstr.).

WOOD J. D., 1973. The fatty acid composition of backfat from Piétrain and Large White pigs. Anim. Prod., 17, 281-285.

WOOD J. D., 1974. Fat mobilization in Large White pigs. Proc. Nutr. Soc., 33. 61A (abstr.).

WOOD J. D., ENSER M. B., RESTALL D. J., 1975. Fat cell size in Piétrain and Large White pigs. J. agric. Sci. Comb., 84, 221-225.

ZINDER O., SHAPIRO B., 1971. Effect of cell size on epinephrine and ACTH-induced fatty acid release from isolated fat cells. J. Lipid. Res., 12, 91-95. 